This item was submitted to Loughborough's Research Repository by the author.

Items in Figshare are protected by copyright, with all rights reserved, unless otherwise indicated.

\title{
The capability of graphene on improving the electrical conductivity and anti- corrosion properties of Polyurethane coatings
}

PLEASE CITE THE PUBLISHED VERSION

http://dx.doi.org/10.1016/j.apsusc.2017.02.081

\section{PUBLISHER}

(C) Elsevier

VERSION

AM (Accepted Manuscript)

\section{PUBLISHER STATEMENT}

This work is made available according to the conditions of the Creative Commons Attribution-NonCommercialNoDerivatives 4.0 International (CC BY-NC-ND 4.0) licence. Full details of this licence are available at: https://creativecommons.org/licenses/by-nc-nd/4.0/

\section{LICENCE}

CC BY-NC-ND 4.0

\section{REPOSITORY RECORD}

Tong, Yao, Siva Bohm, and Mo Song. 2017. "The Capability of Graphene on Improving the Electrical Conductivity and Anti-corrosion Properties of Polyurethane Coatings". figshare.

https://hdl.handle.net/2134/24393. 


\title{
The capability of graphene on improving the electrical conductivity and anti-corrosion properties of Polyurethane coatings
}

\author{
Yao Tong ${ }^{1}$, Siva Bohm ${ }^{2}$ and Mo Song ${ }^{1 *}$ \\ 1: Department of Materials, Loughborough University, Loughborough LE11 3TU, UK \\ 2: Talga Resourses Ltd, Level 1, 2 Richardson Street, West Perth Western Australia 6005 \\ Corresponding author: Song M, Department of Materials, Loughborough University, Loughborough \\ LE11 3TU, UK, Tel.: +44 1509 223331; Fax: +44 1509223949 Email: m.song@lboro.ac.uk (Mo Song)
}

\begin{abstract}
Graphite and graphene particles were used to reinforce the electrical conductivity and anti-corrosion properties of polyurethane (PU) coatings. The effect of graphite and graphene were compared. Hybrid filler using carbon nanotube was adopted as well and the performance in electrical conductivity was much superior to single filler system. At the same filler loading, the electrical conductivity of hybrid filler system was significantly higher than single filler system $(0.77 \mathrm{~S} / \mathrm{m}$ at $5 \mathrm{wt} \%$ while single filler system was not conductive). The conductive mechanism was revealed. In terms of anti-corrosion properties, the coatings with low filler loading had better anticorrosion properties. The resistance values obtained from EIS (Electrochemical Impedance Spectroscopy) and four point probe method were compared and discussed.
\end{abstract}

Key words: Graphene, PU coating, Electrical conductivity, Anti-corrosion, Steel, EIS 


\section{Introduction}

Electricity Energy Storage (EES) is a process that converts electrical energy from generating plants into other forms that can be stored and convert back to electrical energy when needed. The EES technologies are widely used for either potable (mobile phone batteries) or stationary energy resources (pump hydroelectric storage) $[1,2]$. The technologies development is very fast which urge the EES industries to revolve. Apart from the traditional applications in utility and consumer use, there are a lot of new applications arisen such as renewable energy generation, smart house and electrical vehicles [3]. The future market potential of EES, driven by the extended utilization of renewable energy and the transformation of the energy sector, expands rapidly and will be much larger than the existing market which requires the EES industries to advance their technologies and products very fast. The general properties of EES are energy capacity, power, discharge time, lifetime and unit sizes. The electrical conductivity of the components in the EES devices relates to the energy capacity, power, discharge time and even unit sizes while the corrosion resistance of the components is one of the factors that determine the lifetime of EES devices $[3,4]$.

When EESs are in service, the materials of the EES contact different environments, some of which are very corrosive (i.e. metal panels in fuel cell). The reactions between the materials and the environments will destroy or deteriorate the materials and this process is defined as corrosion [5]. Corrosion causes tremendous economic loss and it is a significant part of the gross national production every year in USA [6]. and the estimated annual cost is about 2000-3000 dollars per inhabitant in 1985 [7]. The protection against corrosion is vital to reduce the cost of the products. There are several methods to protect the materials against corrosion (metals substrate in EES devices. The use of coating is the most popular one and about $90 \%$ of all metal surfaces are covered with protective coatings. The protection efficiency of the organic coating is magnificent due to the fact that they are very thin (thickness ranges from 5 microns to 250 microns depend on the applications) [8]. There are three mechanisms of organic coating systems against corrosion: the physicochemical (barrier) mechanism, the electrochemical mechanism (inhibition or cathodic protection) and the adhesion mechanism [9]. Although organic coatings are ideal to protect metal 
substrates from corrosion, they may not suitable for the protection of EES devices as their electrical conductivities are very low which will affect the performance of the devices. The protective coatings used for EES should process good electrical conductivity and anti-corrosion properties [10]. Although the organic coatings have excellent anti-corrosion properties, they do not process acceptable electrical conductivity. In terms of EIS measurement, the electrical resistance of the coating is used as the indication of its efficiency to block the ions that damage the metal substrates [8]. Therefore, an organic coating with excellent anti-corrosion properties may not have good electrical conductivity.

Graphene is a miracle material that has been received widely attentions from the researchers and it has been utilised in many apparitions including conductive nanocomposites. Polypyrrole (PPy)/reduced graphene oxide nanocomposite had been prepared successfully with enhanced electrical conductivity [11]. The electrical conductivity of pure PPy was $0.19 \mathrm{~S} / \mathrm{cm}$ while the $1 \mathrm{wt} \%, 2 \mathrm{wt} \%$ and $3 \mathrm{wt} \% \mathrm{PPy} / \mathrm{GO}$ nanocomposite showed $0.51 \mathrm{~S} / \mathrm{cm}, 1.41 \mathrm{~S} / \mathrm{cm}$ and $1.64 \mathrm{~S} / \mathrm{cm}$, respectively. After reduction, the nanocomposites could exhibit better electrical conductivity. The electrical conductivity of thermal plastic PU was improved by adding reduced graphene oxide into the PU matrix by Canales and his colleagues. The highest electrical conductivity achieved was $6.1 \times 10^{-4} \mathrm{~S} / \mathrm{cm}$ [12]. ABA (4-aminobenzoic acid) functionalized graphene was incorporated in PANI for corrosion protection coatings [13]. The coatings could protect the steel effectively because of the excellent $\mathrm{O}_{2}$ and $\mathrm{H}_{2} \mathrm{O}$ barrier. Due to the high aspect ratio of graphene, it can be a more efficient gas brier than other nanofillers. Parasai and his co-workers developed single-layer and multi-layer graphene films to serve as anti-corrosion coatings [14]. The coatings can be applied on different metallic substrates. The impedance values of the graphene coated metal were much higher than pure metal. From the previous work, graphene is promising to be utilised to improve the electrical conductivity and anti-corrosion properties of polymer. 
It is not easy to develop an organic coating with excellent electrical conductivity and anti-corrosion properties at the same time. The coating industry has been undergoing a continual change in technology in the last few decades. With the discovery of new materials and the change in international legislation, the formulation of coatings has been changed significantly. Graphene is a promising materials and its potential use in coating is huge. The wide utilisation and excellent properties of PU make it excellent candidate as anti-corrosion coatings. The combination of graphene and PU may able to produce a coating with good electrical conductivity and anti-corrosion properties. The porous surface of the EPD coated metal substrates in our previous published paper can be covered by PU/graphene nanocomposite coatings [15]. The researches reporting anti-corrosion properties and electrical conductivity at the same time are limited. The multi-layers coating system will be discussed in this chapter as well. The coated samples will be characterised by EIS and four point probe test for anticorrosion property and electrical conductivity respectively. The coating resistance obtained with different technique will be discussed. In this paper, EIS is used to predict the anti-corrosion properties of the prepared coatings and reveal the effect of graphene on the anti-corrosion properties. 


\section{Experiments}

\subsection{Materials}

TIMREX PP10 natural graphite (PP10) which supplied by TATA steel was purchased from TIMCAL Ltd. The expandable graphite was purchased from China Qing Dao Graphite Company. MWCNT was purchased from a company in China. PU topcoat and primer were supplied by TATA steel. Cold rolled steel 'Black Plate', which was used as substrates, was provided by TATA Steel R\&D. Acetone (99.5\% purity) and iodine were purchased from Sigma Aldrich. $\mathrm{NaCl}$ was purchased from Fisher Ltd (UK).The graphene used was the same as our previous work [15].

\subsection{Sample preparation}

For the fabrication of nanocomposite coatings PP10, MWCNT and TEG were used. Initially, topcoat was stirred by a glass rod to let the polymer particles disperse uniformly in the suspension and then a calculated amount of PU topcoat was poured into a glass bottle for latter mechanical stirring. The total weight of the composite was $6 \mathrm{~g}$. A calculated amount of filler was added into the PU topcoat during mechanical stirring. The duration of mechanical stirring was 4 hours

For hybrid filler filled coating, the total weight of the composite was $6 \mathrm{~g}$. According to the filler ratio, calculated amount of TEG, G or PP10 and MWCNTs were added into a glass bottle and a suitable amount of acetone was added as well. The resulted suspension was ultrasonicated for 30 minutes. After ultrasonication, the glass bottle was put into a fume cupboard to evaporate the acetone until a filler paste was resulted. Calculated amount of topcoat was added into the glass bottle and the mixture was mechanical stirred at $1000 \mathrm{rpm}$ for 4 hours. The preparation procedure of primer based nanocomposite coatings was similar.

All the resulted mixtures were coated onto the BP steel by hand draw bar which performed with a glass rod. Before coating, The BP substrates were cleaned by 
acetone and then they were degreased in $5 \%$ alkaline solution at $70{ }^{\circ} \mathrm{C}$ for 3 minutes. The coated samples were put into an oven at $290{ }^{\circ} \mathrm{C}$ for 4 minutes 40 s for fully cured. For EPD + topcoat system, topcoat was directly coated onto EPD deposited layer by hand draw bar. The as-prepared sample was cured at the same conditions as other samples. For multi-layer system, epoxy primer was directly coated onto EPD deposited layer by hand draw bar and cured in the oven at $290{ }^{\circ} \mathrm{C}$ for 3 minutes. PU top coat was subsequently coated onto the coated sample by hand draw bar and the resulted multi-layers coating was punt into the oven for 4 minutes $40 \mathrm{~s}$. The EPD coated sample was produced according to previous paper. The coating thickness limit of EPD coating is $10 \mu \mathrm{m}$ and the coating thickness limit of the polymeric coatings are $4 \mu \mathrm{m}$.

\section{Characterization}

The electrical conductivity of the coated samples was measured by using a FLUKE PM6306 programmable automatic RCL meter with a four point probe. Relative electrical conductivity $\mathrm{C}_{\mathrm{c}} / \mathrm{C}_{\mathrm{s}}$ was used show the electrical conductivity enhancement, where $\mathrm{C}_{\mathrm{c}}$ represents the measured electrical conductivity of the coated samples and $\mathrm{C}_{\mathrm{s}}$ represents the measured electrical conductivity of bare steel. Optical microscopy (Leica DFC480) and FEGSEM (Carl Zeis (Leo) 1530VP) were used to characterize the surface of the coated samples. EIS was used to characterize the corrosion resistance of the coatings. The thicknesses of the coatings were measured by calliper. 


\section{Results and Discussion}

\subsection{The electrical conductivity of the nanocomposite coatings}

\subsubsection{The conductivity of PU topcoat composites}

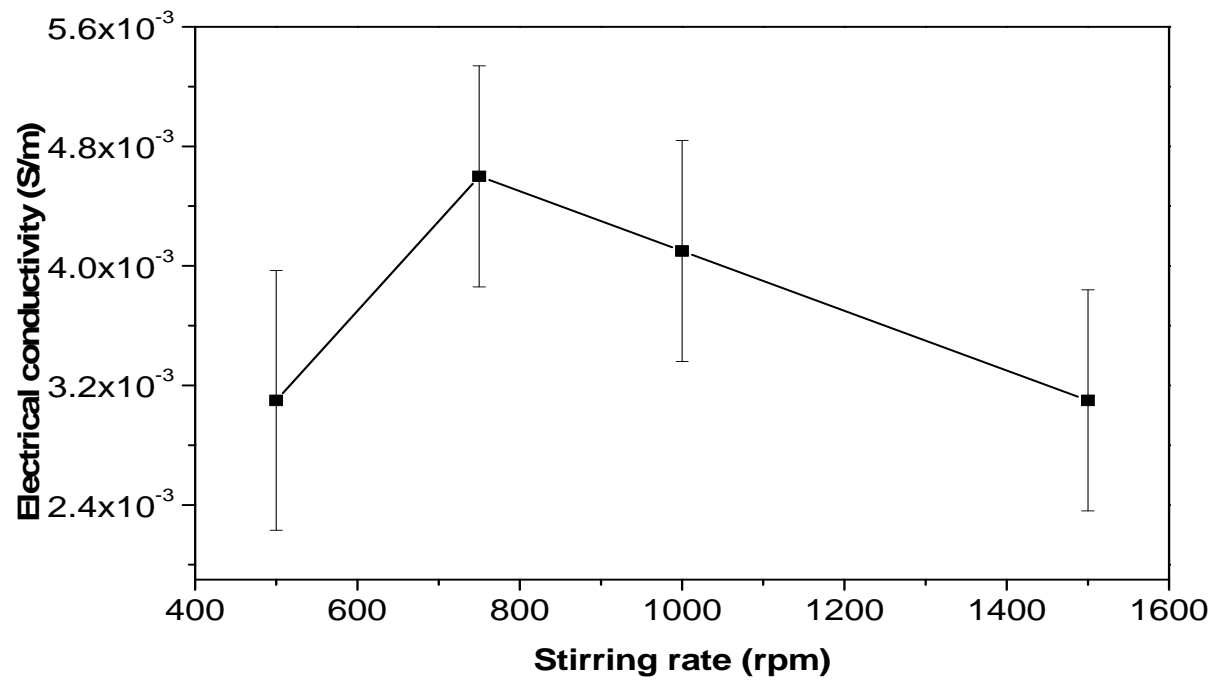

Figure 1 Plot of electrical conductivity versus stirring rate (topcoat trials)

Figure 1 shows the electrical conductivity versus stirring rate of $8 \mathrm{wt} \%$ PP 10 filled PU topcoat. The stirring rates are selected according to general stirring rates used in TATA Steel. It seems that $750 \mathrm{rpm}$ stirring rate is an ideal stirring rate to achieve higher conductivity. However, the conductivity only changed from 0.0032 to 0.0046 which indicates that stirring rate does not affect the electrical conductivity significantly. In addition, the electrical conductivity may actually near the same when the standard deviation is considered. Therefore, stirring rate did not have a profound effect on the electrical conductivity and the function of stirring is to disperse the particles uniformly in the coating. 


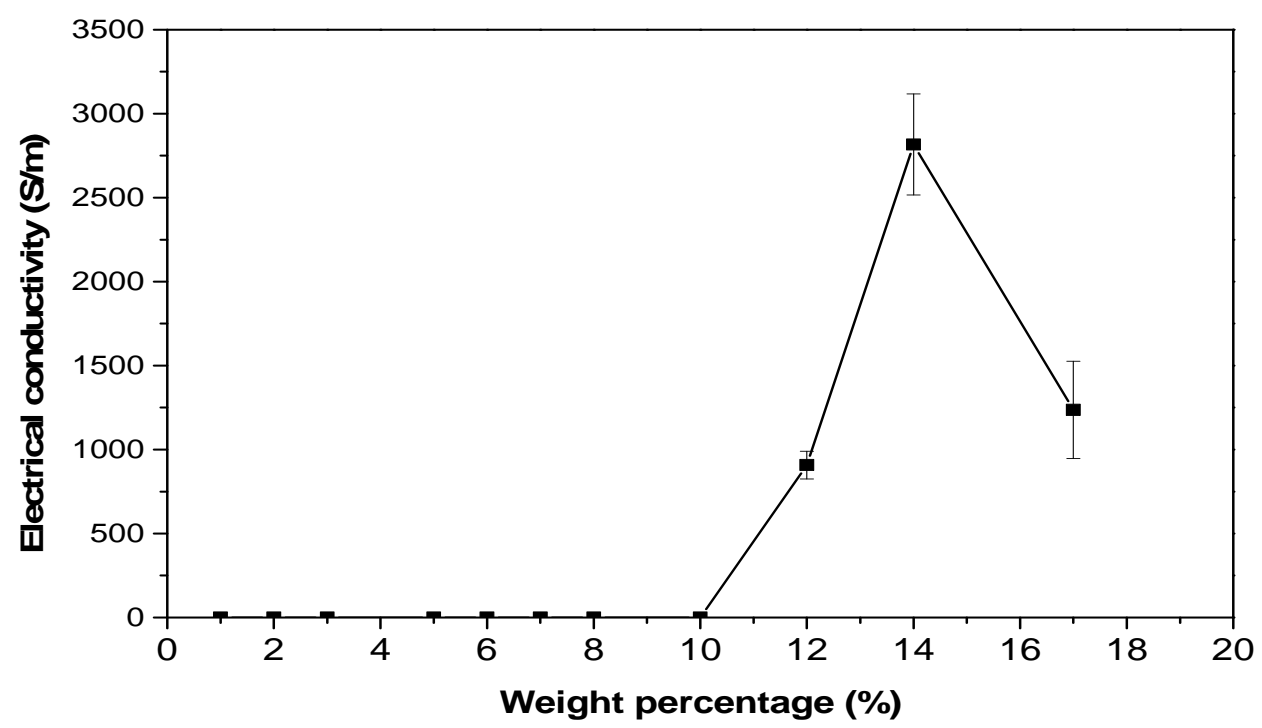

Figure 2 Plot of electrical conductivity versus PP10 weight percent for PPPU trials

Table 1 Electrical conductivity values of PPPU system

\begin{tabular}{|c|c|c|c|c|c|c|}
\hline Code name & PPPU7500 & PPPU8500 & PPPU10500 & PPPU12500 & PPPU14500 & PPPU17500 \\
\hline $\begin{array}{l}\text { Electrical } \\
\text { conductivity } \\
(\mathrm{S} / \mathrm{m})\end{array}$ & $\begin{array}{l}7.42 \mathrm{E}-4 \quad \pm \\
1 \mathrm{E}-4\end{array}$ & $\begin{array}{l}3.2 \mathrm{E}-3 \quad \pm \\
3 \mathrm{E}-4\end{array}$ & $0.21 \pm 0.01$ & $907.75 \pm 82$ & $\begin{array}{ll}2816.9 \quad \pm \\
201.3\end{array}$ & $\begin{array}{ll}1336.2 \quad \pm \\
290.6\end{array}$ \\
\hline
\end{tabular}

Figure 2 and Table 1 show the electrical conductivity of the coatings in PPPU trial. From the results, $14 \mathrm{wt} \% \mathrm{PP} 10 / \mathrm{PU}$ coating has the highest conductivity and the percolation threshold of this system is $7 \mathrm{wt} \%$. The reason why $14 \mathrm{wt} \% \mathrm{PP} 10 / \mathrm{PU}$ coating has best conductivity is that the contact resistance and tunnelling resistance between the PP10 particles are the lowest. The distance between the dispersed PP10 particles in the PU matrix is the key factor that affects the electrical conductivity. A polymer composite can only be conductive when the distance between two conductive filler particles less than 2 3 nm [16]. With more PP10 particles added into the matrix, current can pass through the coating layer with less resistance which lead to higher electrical conductivity. However, if excessive amount of PP10 is added, the contact resistance between PP10 particles has a detrimental effect on the resulted coating's conductivity. This is the reason why the electrical conductivity begins to drop when the PP10 loading is larger than $14 \mathrm{wt} \%$. 


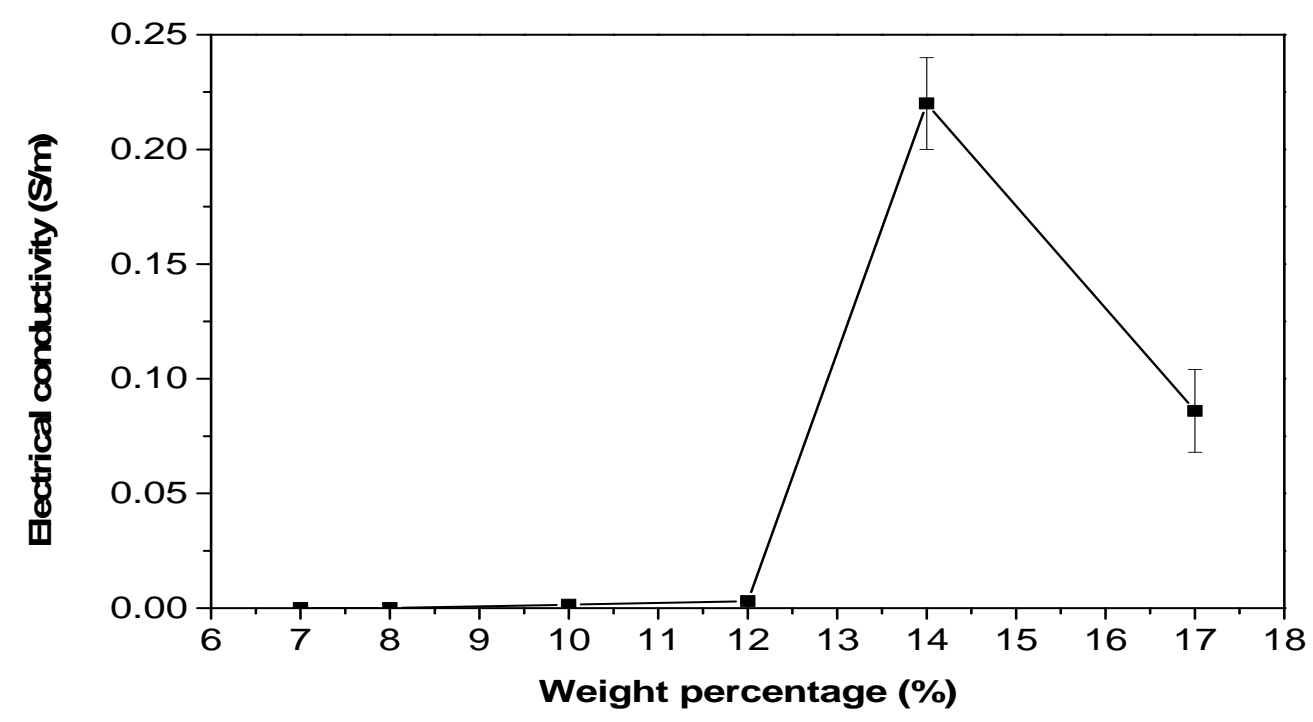

Figure 3 Plot of electrical conductivity versus PP10 weight percent for EPPPU trials

Table 2 Electrical conductivity values of EPPPU system

\begin{tabular}{|c|c|c|c|c|c|c|}
\hline Code name & EPPPU7500 & EPPPU8500 & EPPPU10500 & EPPPU12500 & EPPPU14500 & EPPPU17500 \\
\hline $\begin{array}{c}\text { Electrical } \\
\text { conductivity }\end{array}$ & 0 & 0 & $7 \mathrm{E}-4 \pm 1.2 \mathrm{E}-$ & $3.4 \mathrm{E}-3 \pm$ & & \\
$\mathbf{( S / m )}$ & & & 4 & $1.9 \mathrm{E}-3$ & $0.22 \pm 0.056$ & $0.086 \pm$ \\
\end{tabular}

Figure 3 and Table 2 show the electrical conductivity of EPPPU coating systems. EPPPU system is a two layers coating system where primer is underneath the top coating. Compared to PPPU system, similar trend of electrical conductivity versus PP10 weight percent is observed. In addition, the electrical conductivity of EPPPU coated samples are much lower than PPPU coated samples which indicate that the application of primer significantly reduce the electrical conductivity due to the insulation effect.

Table 3 Electrical conductivity of PPPU topcoat

\begin{tabular}{|c|c|c|}
\hline Coating system & PU top coat & EPD + PU top coat \\
\hline Electrical conductivity (S/m) & $0.0032 \pm 0.0003$ & $0.31 \pm 0.02$ \\
\hline
\end{tabular}

From Table 3, the application of EPD coating layer prior to PU topcoat can significantly enhance the electrical conductivity of the coating system. PU topcoat acts as barrier layer in this system. As a result of the deposited graphite layer has very 
high electrical conductivity, the electrical conductivity of the topcoat is improved because more electrical conductance is presented in the system. In addition, the distance between the EPD layer and the PU topcoat is very close and, therefore, the tunnelling resistance is very low.

\subsubsection{The conductivity of PU primer composites}

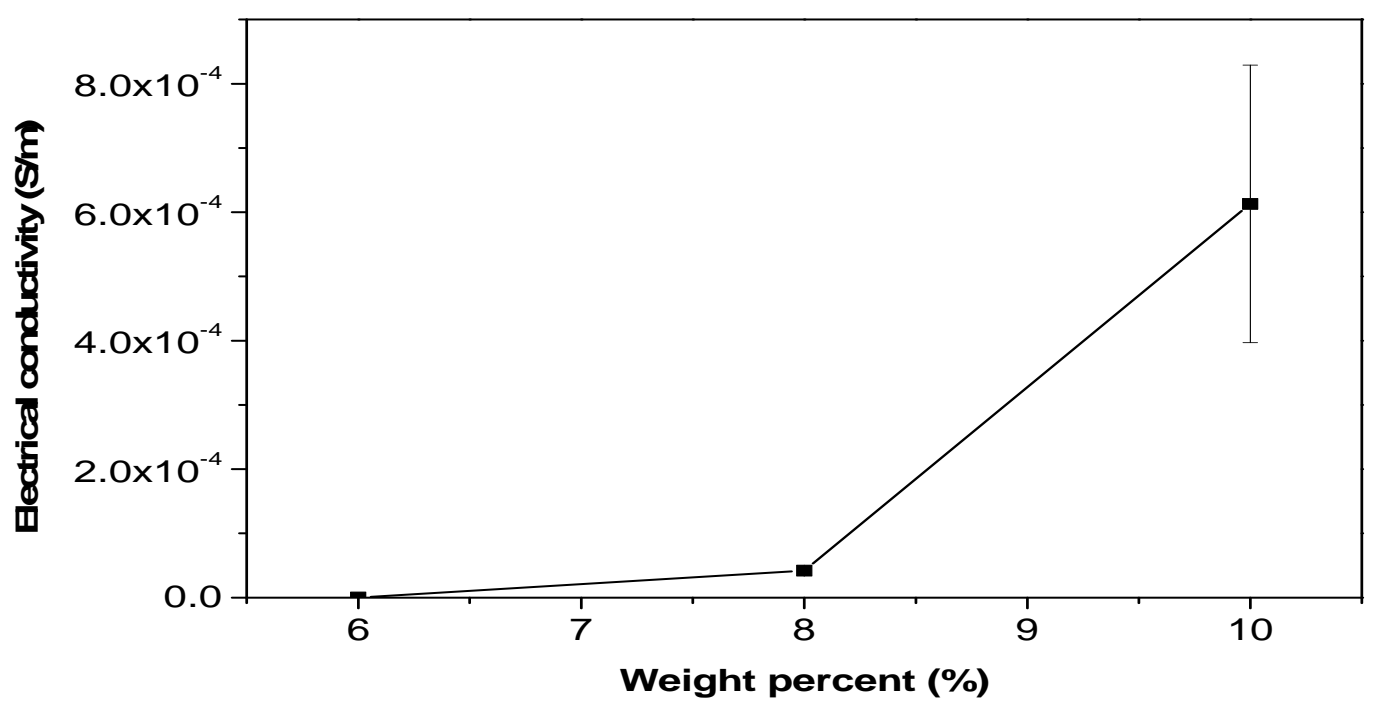

Figure 4 Plot of electrical conductivity versus PP10 weight percent for EPP primer trials

Table 4 Electrical conductivity EPP system

\begin{tabular}{|c|c|c|c|}
\hline Code name & EPP6500 & EPP8500 & EPP10500 \\
\hline Electrical conductivity (S/m) & 0 & $4.21 \mathrm{E}-5 \pm 7.4 \mathrm{E}-6$ & $6.13 \mathrm{E}-4 \pm 2.16 \mathrm{E}-4$ \\
\hline
\end{tabular}

Figure 4 and Table 4 show the electrical conductivity of the coatings in EPP trial. From the results, the percolation threshold of this system is $8 \mathrm{wt} \%$. Compared to the electrical conductivity of conductive top coat, the electrical conductivity values of primer/PP10 composite coating are generally lower. The reason is that the primer has higher viscosity than PU top coat. Agglomerates of PP10 particles were formed during stirring and the particles could not be dispersed effectively. As discussed before, the distance between the dispersed PP10 particles in the coating is the key factor that affects the electrical conductivity. With agglomerates of PP10 particles 
formed, the distance between each particle will be larger and the tunnelling resistance will be increased. Higher viscosity of primer system leads to poorer electrical conductivity performance than PU top coat system.

\subsubsection{The conductivity of hybrid filler system and multi-layer coating}

Table 5 Electrical conductivity of hybrid filler PU topcoat system

\begin{tabular}{|c|c|c|c|}
\hline Code name & HIPU81000 & HIIPU81000 & HIIIPU81000 \\
\hline Electrical conductivity (S/m) & $0.14 \pm 0.01$ & $2567.4 \pm 235$ & $2 \mathrm{E}-3 \pm 2.8 \mathrm{E}-4$ \\
\hline
\end{tabular}

In hybrid filler system, the addition of CNTs can improve the electrical conductivity of the system significantly as shown in Table 5. The tube shape CNT can act as a bridge between PP10 particles to form a conductive network. Therefore, the tunnelling resistant of this coating system is reduced significantly and the resistance of this system is mainly the contact resistance between filler particles. The addition of graphene does not show obvious enhancing effect. The addition of CNT can improve the electrical conductivity of the coating significantly. The role of PP10 particles act as the island of the conductive network. Therefore, the combination of these bridges and islands allow the current to flow without high resistance.

Table 6 Electrical conductivity of hybrid filler primer system

\begin{tabular}{|c|c|c|}
\hline Coating system & HIIEPP4500 & HIIEPP8500 \\
\hline Electrical conductivity (S/m) & $4.2 \mathrm{E}-3 \pm 5 \mathrm{E}-4$ & $0.4 \pm 0.12$ \\
\hline
\end{tabular}

From Table 6, the addition of MWCNTs into the system can significantly improve the electrical conductivity of primer system. However, the electrical conductivity hybrid filler epoxy primer is poorer than hybrid filler PU top coat with the same weight percent of hybrid filler incorporated. The results are as expected. With the addition of MWCNTs, the percolation threshold of epoxy primer system was much lower than the system where only PP10 was added. The high aspect ratios and tube shape of MECNTs can facilitate the formation of conductive network in the coating system. As a result of MWCNTs' structure, the tunnelling resistance in the coating system is reduced significantly. 
Table 7 Electrical conductivity of hybrid filler primer system

\begin{tabular}{|c|c|c|c|c|}
\hline Code name & MI(1) & MI(2) & MII(1) & MII(2) \\
\hline Electrical conductivity (S/m) & $4.92 \pm 0.78$ & $1.71 \pm 0.28$ & $2.54 \pm 0.29$ & $1.14 \pm 0.18$ \\
\hline
\end{tabular}

After the trials of hybrid filler system, the produced coatings were used to investigate the performance of multi-layers coating. The electrical conductivity of the multi-layer coating systems are shown in Table 7. From both trials, the systems (MI(1) and MII(2)) containing EPP8500 primer have higher conductivity. Comparing the three layers and two layers coatings (MII), the three layers coating systems (MI) have higher conductivity due to the EPD coating layer. However, multi-layers coating systems have much lower electrical conductivity than single layer coating system. With the application of second coating layer, the tunnelling resistant and contact resistance of the whole system will be increased because the addition of extra insulation polymeric component in the system. In addition, the interface between two coatings may act as insulated layer because they polymers near the interface act as barrier to separate the conductive particles between the two coatings. The tunnelling resistance of the whole system will be increase significantly as the conductive particles are not close enough to each other to let the current pass through without much resistance. The application of EPD layer can only improve the electrical conductivity of the whole coating system a little because the insulation effect resulted from the polymeric component is too significant.

Table 8 Electrical conductivity of second set of hybrid filler primer

\begin{tabular}{|c|c|c|c|}
\hline Code name & HIVE 21000 & HVE21000 & HVIE21000 \\
\hline $\begin{array}{c}\text { Electrical conductivity } \\
(\mathbf{S} / \mathbf{m})\end{array}$ & $1.96 \mathrm{E}-3 \pm 3.6 \mathrm{E}-4$ & $4.8 \mathrm{E}-4 \pm 7.2 \mathrm{E}-4$ & $2.26 \mathrm{E}-3 \pm 5.34 \mathrm{E}-4$ \\
\hline
\end{tabular}

In order to improve the electrical conductivity of the coating further, a new filler TEG was utilized. Table 8 shows the electrical conductivity of coating contained different ratios of hybrid fillers. From the results, the sample with the TEG to MWCNTs ratios of 2:1 (HIVE21000) has the lowest electrical conductivity while the electrical conductivity of HIVE21000 and HVIE21000 is the nearly same. MWCNTs could act as bridge between TEG particles so the current can pass through the sample with less 
resistance and, therefore, the electrical conductivity of the samples increases with more MWCNTs in the hybrid filler. However, the bridging effect of MWCNTs becomes less profound when MWCNTs to TEG ratio is bigger than 1. Hence, the effect of weight percent on electrical conductivity was investigated by fabricating HIVE samples with different weight percent of hybrid fillers.

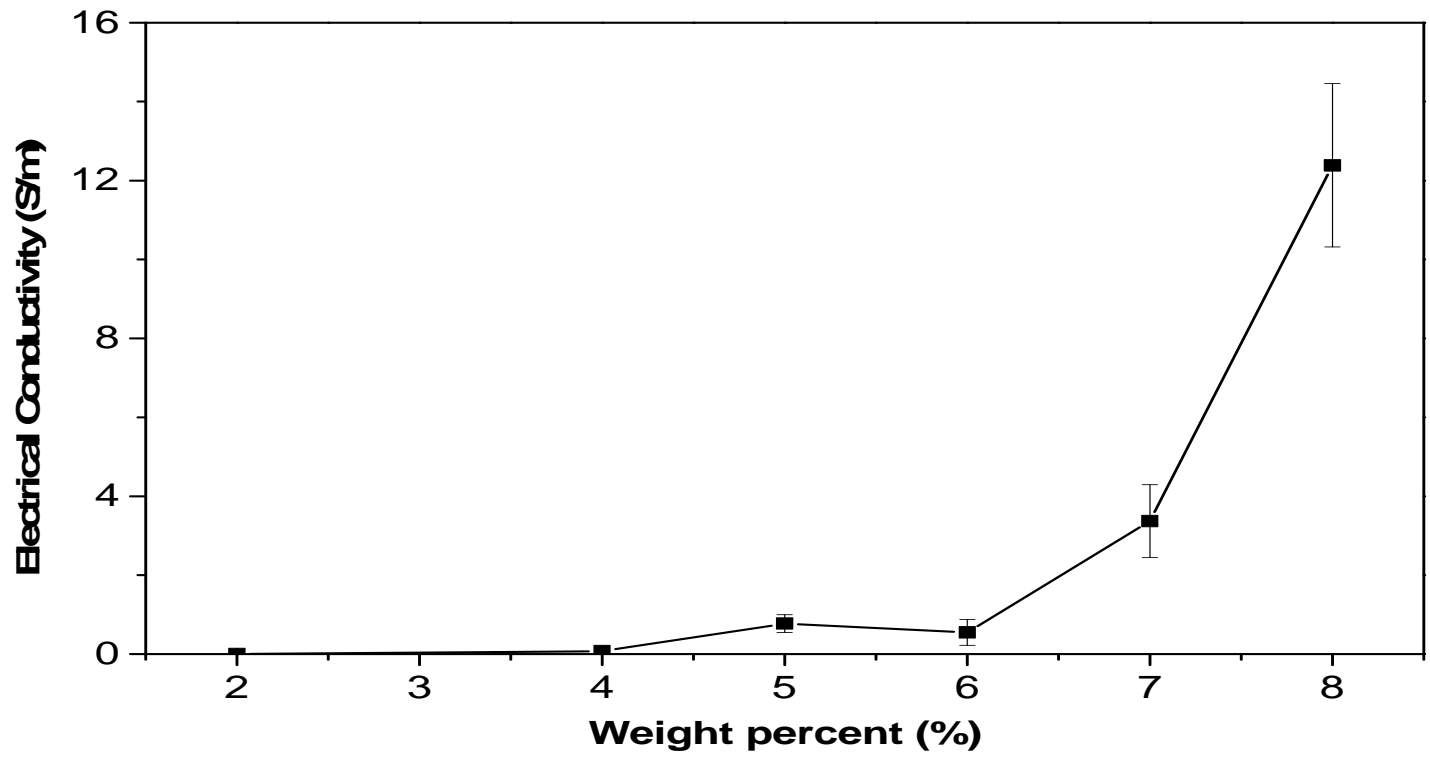

Figure 5 Plot of electrical conductivity versus hybrid filler weight percent of HIVE

Table 9 Electrical conductivity, resistance, conductivity ratios of hybrid filler filled primer samples primer system

\begin{tabular}{|c|c|c|c|c|c|c|}
\hline Code name & HIVE21000 & HIVE41000 & HIVE51000 & HIVE61000 & HIVE7000 & HIVE81000 \\
\hline $\begin{array}{c}\text { Electrical } \\
\text { conductivity } \\
(\mathbf{S} / \mathbf{m})\end{array}$ & $\begin{array}{c}1.96 \mathrm{E}-3 \pm \\
3.6 \mathrm{E}-4\end{array}$ & $\begin{array}{c}0.073 \\
\pm 0.013\end{array}$ & $0.77 \pm 0.22$ & $0.54 \pm 0.32$ & $3.37 \pm 0.93$ & $12.37 \pm 2.1$ \\
\hline $\begin{array}{c}\text { Resistance } \\
(\boldsymbol{\Omega})\end{array}$ & $1.16 \mathrm{E} 6 \pm$ & $30849 \pm 581$ & $3116 \pm 465$ & $5167 \pm 577$ & $701 \pm 188$ & $183 \pm 30$ \\
\hline $\begin{array}{c}\text { Conductivity } \\
\text { ratios } \mathbf{C}_{\mathbf{c}} / \mathbf{C}_{\mathbf{s}}\end{array}$ & $\begin{array}{c}6.67 \mathrm{E}-7 \pm \\
1.2 \mathrm{E}-7\end{array}$ & $\begin{array}{c}2.51 \mathrm{E}-5 \\
\pm 4.4 \mathrm{E}-6\end{array}$ & $\begin{array}{c}2.62 \mathrm{E}-4 \pm \\
7.6 \mathrm{E}-5\end{array}$ & $\begin{array}{c}1.87 \mathrm{E}-4 \\
\pm 1.1 \mathrm{E}-5\end{array}$ & $\begin{array}{c}1.2 \mathrm{E}-3 \pm 3.15 \mathrm{E}- \\
4\end{array}$ & $\begin{array}{c}4.21 \mathrm{E}-3 \\
\pm 7.04 \mathrm{E}-4\end{array}$ \\
\hline
\end{tabular}

Figure 5 shows the electrical conductivity of HIVE samples contained different weight percent of hybrid fillers. The values of electrical conductivity resistance and 
conductivity ratios of HIVE samples are shown in Table 9. With the addition of hybrid filler, the electrical conductivity of primer increase significantly. The resistance of HIVE samples was lower than $1000 \Omega$ when the hybrid filler weight percent was higher than $7 \mathrm{wt} \%$. The percolation threshold of HIVE system was significantly lower than the systems in the reports before. The addition of TEG provided superior electrical conductivity than the materials used before.

Table 10 Electrical conductivity comparison of the samples with and without slat addition

\begin{tabular}{|l|l|l|l|}
\hline \multicolumn{1}{|c|}{ Code name } & \multicolumn{1}{|c|}{$\begin{array}{c}\text { Electrical } \\
\text { conductivity }(\mathbf{S} / \mathbf{m})\end{array}$} & \multicolumn{1}{c|}{ Resistance $(\mathbf{\Omega})$} & $\begin{array}{c}\text { Conductivity ratios } \\
\mathbf{C}_{\mathbf{c}} / \mathbf{C}_{\mathbf{s}}\end{array}$ \\
\hline HVIE61000 & $0.2 \pm 0.04$ & $11314 \pm 1047$ & $6.85 \mathrm{E}-5 \pm 1.3 \mathrm{E}-5$ \\
\hline $\begin{array}{l}\text { HVIE61000 } \\
\text { salt }\end{array}$ & $0.29 \pm 0.05$ & $7905 \pm 1072$ & $9.83 \mathrm{E}-5 \pm 2.03 \mathrm{E}-5$ \\
\hline
\end{tabular}

Salt $(\mathrm{NaCl})$ addition can improve the electrical conductivity of the conductive primer systems as shown in Table 10. The sample with intermediate electrical conductivity of the hybrid filler primer was selected. Ions will be formed when salt dissolve in the epoxy primer system to act as electrical conductive island to reduce the tunnelling resistance further of the system. The concentration selected was according to the study of Song et al [16]. Excessive slat will reduce the electrical conductivity and might weaken the performance of the coating. In terms of anti-corrosion properties, the addition of salt might accelerate the corrosion process. The ions in the environment (electrolyte such as $\mathrm{NaCl}$ ) need to migrate into the coating and react with the metal substrate. In the coating containing salt, the migration of ions from the environment to substrate might be easier and the failure of coating might be initiated earlier. 


\subsubsection{The Mechanisms of electrical conductivity}

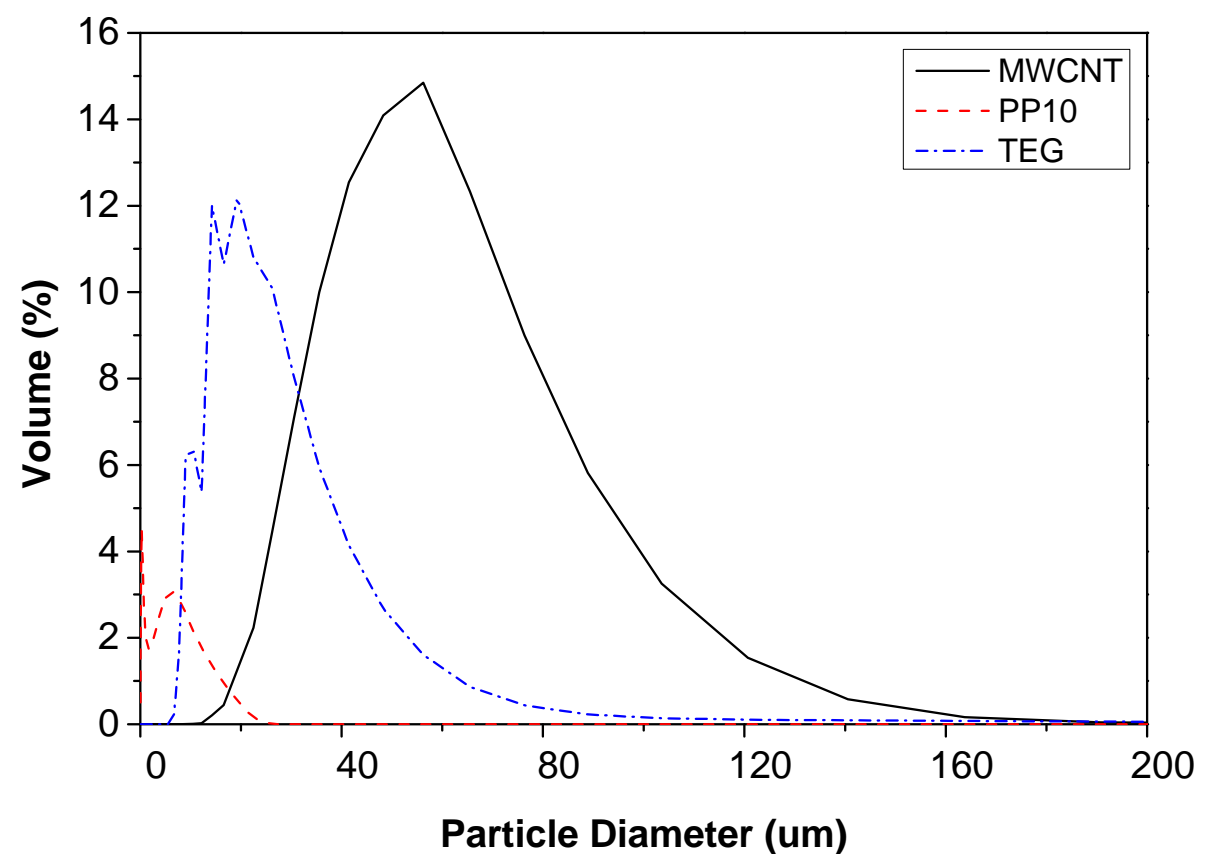

(a)

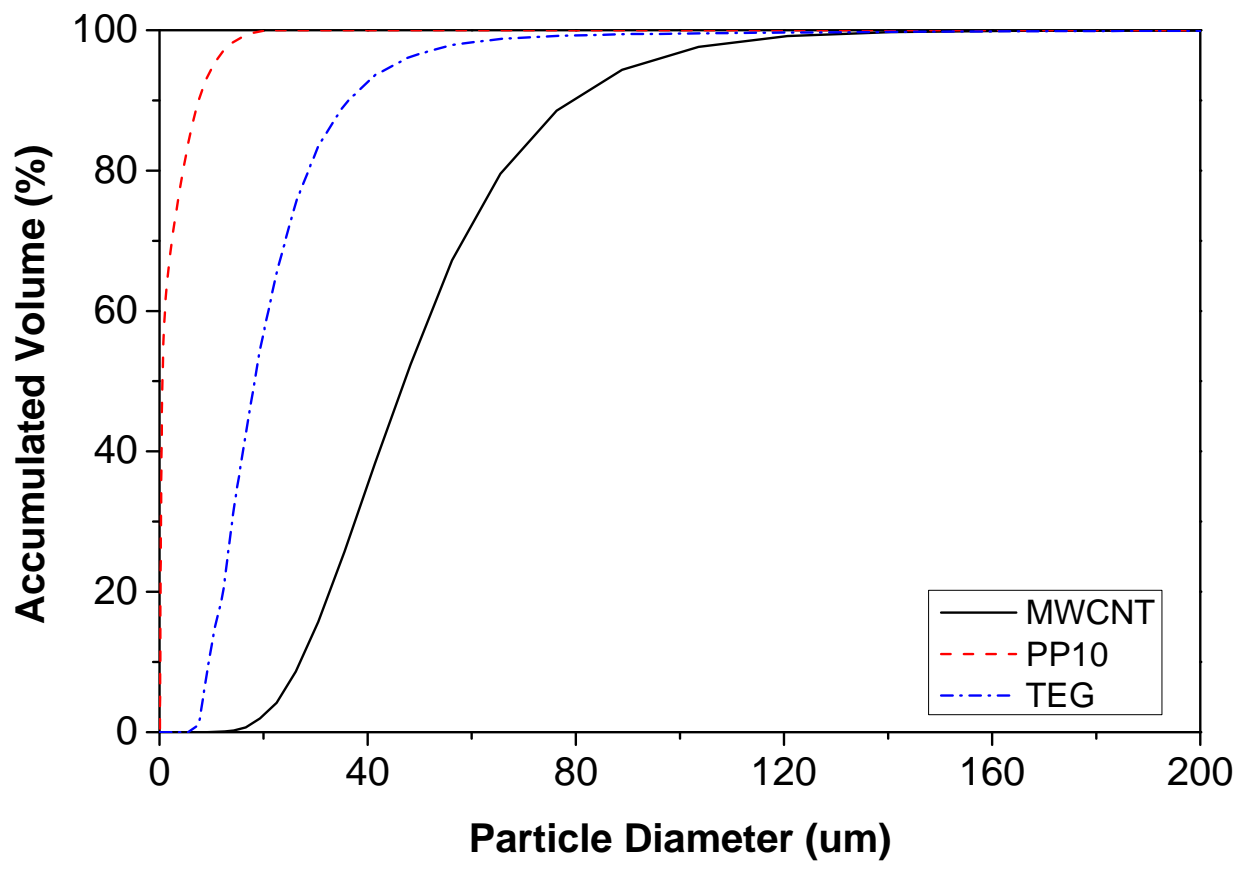

(b)

Figure 6 Plots of (a) particle size distribution of three different fillers (b) Accumulated volume versus particle diameter of three different fillers 


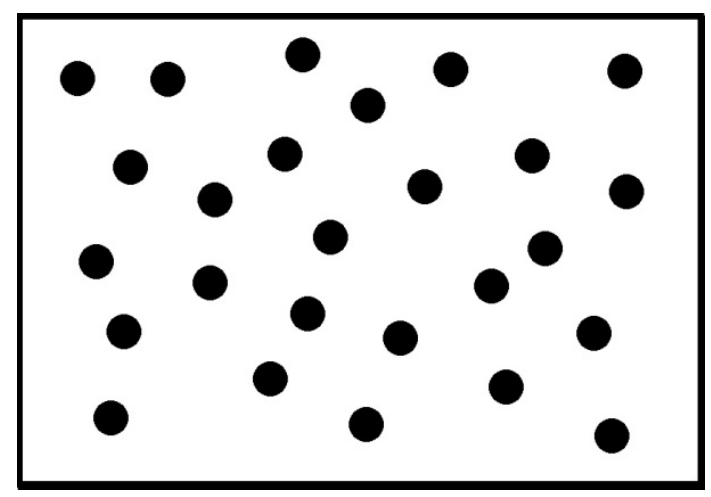

(a)

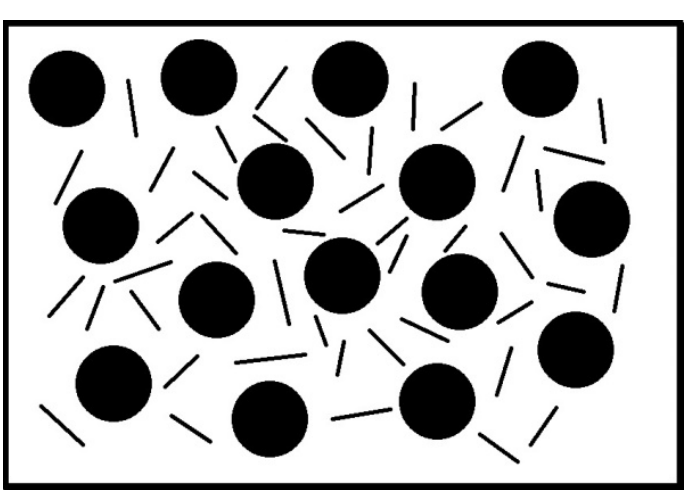

(c)

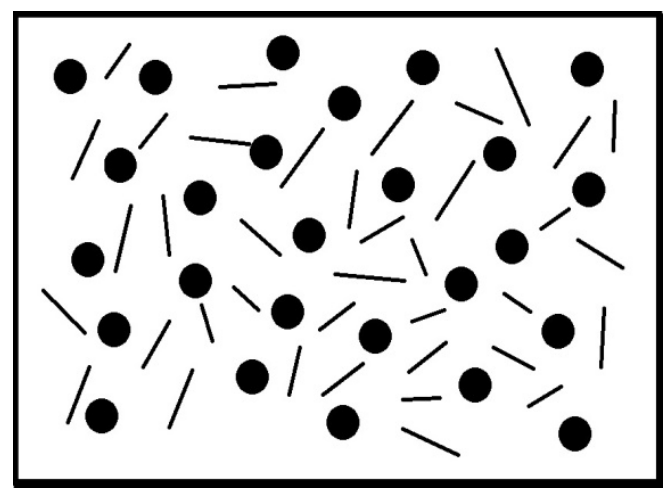

(b)

(c)

Figure 7 Scheme of the filler reinforced coating (a) PP10 (b) PP10 + MWCNT (c) TEG + MWCNT

The key of achieving high electrical conductivity in composite is to reduce the distance between the conductive particles. Increasing the weight percent of the conductive fillers is one of the effective methods. However, the cost of the filler and the reduction in coating properties are the major drawbacks. Hence, increasing the diameter of the filler particles is an alternative way to increase the electrical conductivity without increasing the cost and weakening the coating performance. Figure 6 show the particle size distribution and particle diameter of PP10, TEG and MWCNT. According to the previous result, the hybrid filler system using TEG and MWCNT had higher electrical conductivity. Hence, the bigger size particle can facilitate the formation of conductive network. Due to the reduced distance between the conductive fillers in the system (as shown in Figure 7), the tunnelling resistance of the system is reduced significantly. As a result, the percolation threshold is reduced significantly and the electrical conductivity of the system is improved remarkably. The selection of the filer is vital for the electrical conductivity enhancement. 


\subsection{The anti-corrosion property of the nanocomposite coatings}

\subsubsection{Single filler system}

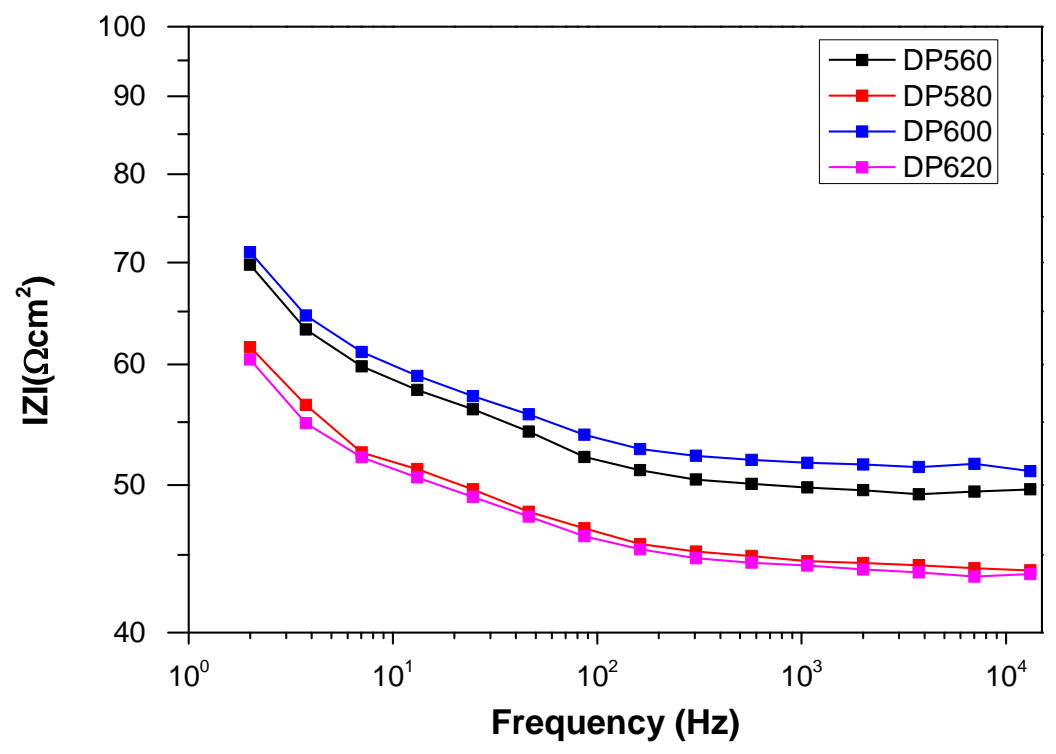

Figure 8 Bode plot of the samples with EPD coating (after heat treatment)

Figure 8 show the impedance versus frequency for some EPD samples after heat treatment. The maximum impedance in Bode plot is a good indication of the coating protection against corrosion [17]. In terms of steel substrate, a good protective organic coating should have the maximum impedance value above $10^{6} \Omega \mathrm{cm}^{2}[18]$.

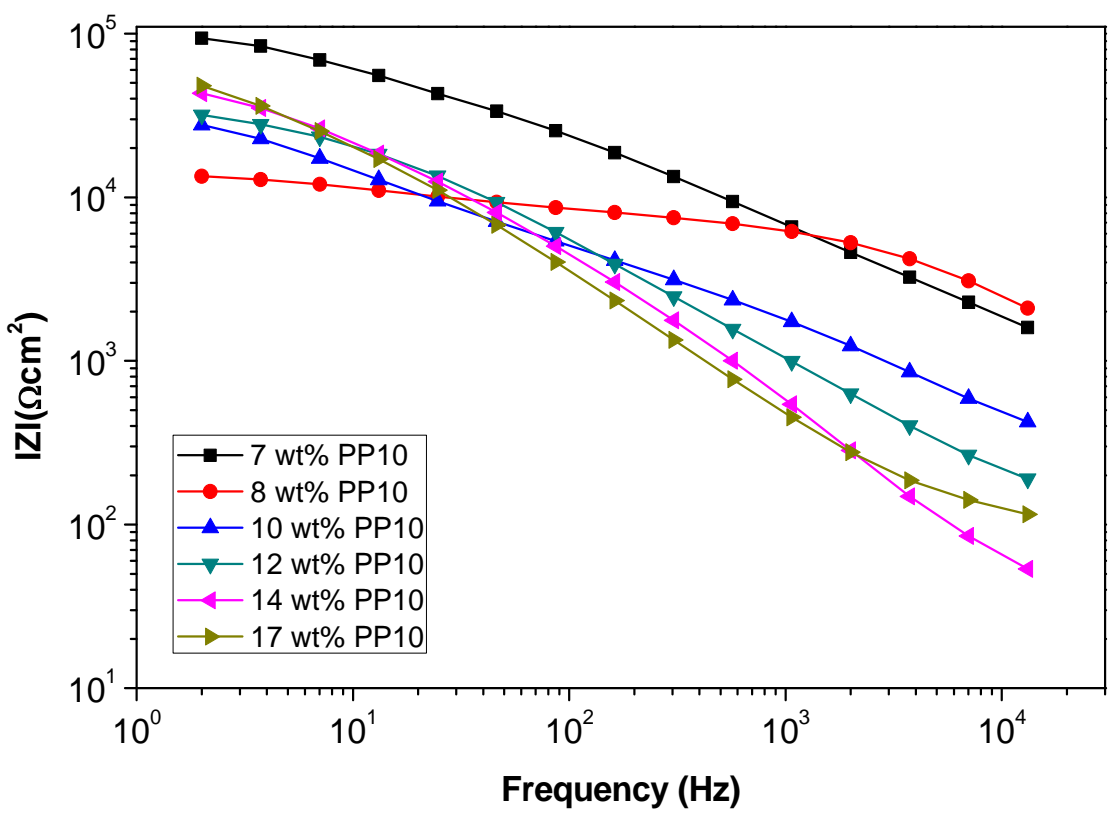

(a) 


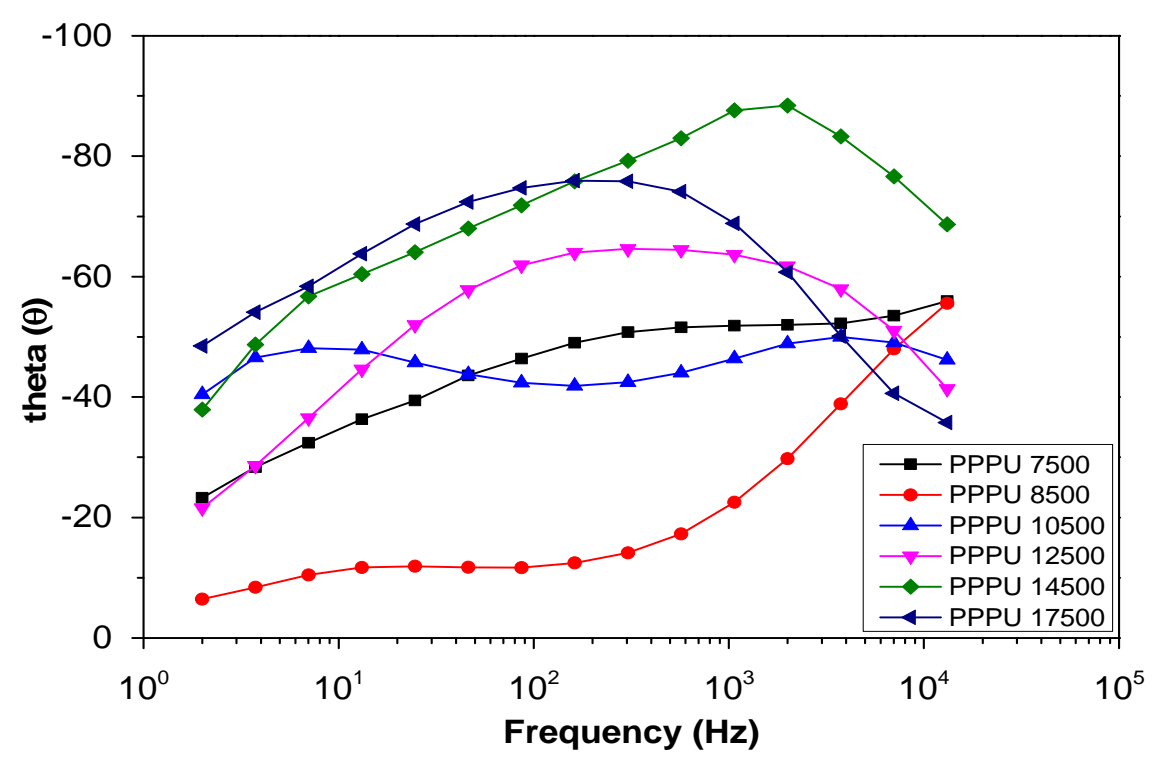

(b)

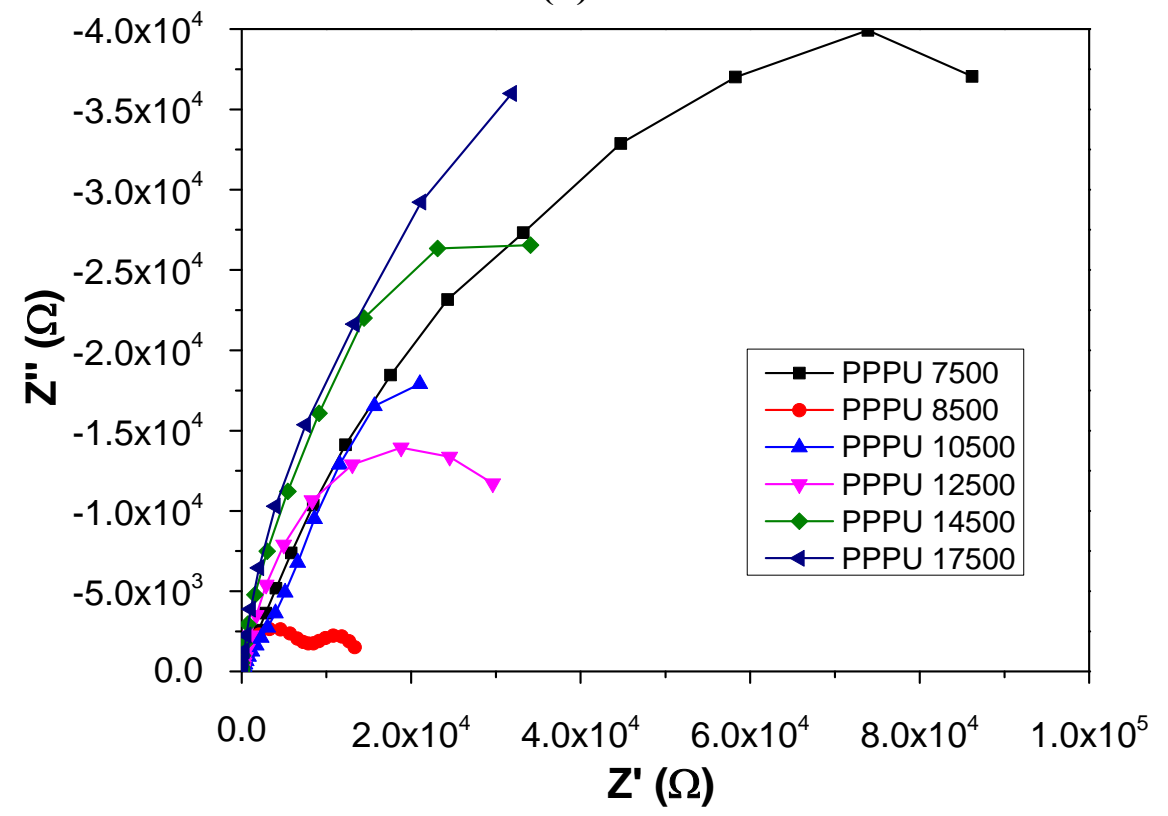

(c)

Figure 9 EIS results of PPPU trial (a) Bode plot (b) Bode phase angle plot (c) Nyquist plot

The EIS results of PPPU trial are shown in Figure 9. The maximum impedance in this frequency range decreases with filler weight percent first and then increases with filler weight percent but the impedance of the sample with $17 \mathrm{wt} \%$ PP10 is lower than that with $7 \mathrm{wt} \%$ PP10. PU/7 wt $\%$ PP10 topcoat has the highest maximum impedance while PU/8 wt \% has the lowest maximum impedance. Although, most of the samples display characteristic of effective barrier film in Nyquist plot, the maximum impedances of all the samples are below $10^{6} \Omega$ which indicate that they cannot serve 
as a good protective coating while maintaining high electrical conductivity. With the increase of PP10 loading, the coating structure was damaged but the diffusion pathways for the corrosive medium was prolonged. That's why the maximum impedance decreases with filler loading first and then increase. The appearance of second semi-circle in Nyquist plot (Figure 9 (c)) suggests that the barrier effect of the film is partially lost and the metal substrate can contact the corrosive medium. All the coatings are tested without any long time exposure to corrosive environment. Therefore, the heterogeneity and the defects induced during preparation are accounted for this phenomenon. The Bode phase angle plot can be used to evaluate the degradation stages of a coating. From Figure 9 (b), PPPU 12500, 14500 and 17500 are approaching to the phase 2 of degradation where the corrosion starts. PPPU 7500 and 10500 are in the phase 1 of degradation where water start to penetrate the coating layer. PPPU 8500 is in the phase 3 of degradation where severe corrosion occurs [19]. Although PPPU 10500 has lower impedance, the lifetime may be longer than PPPU 12500,14500 and 17500.

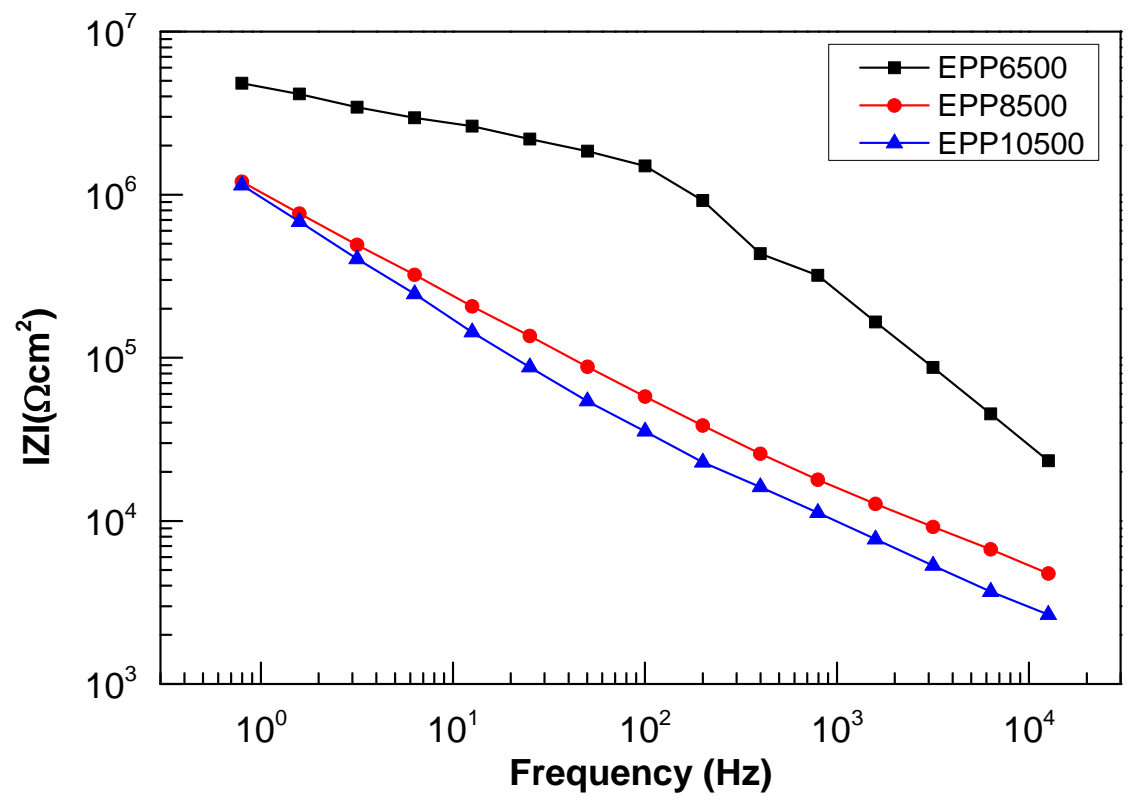

(a) 


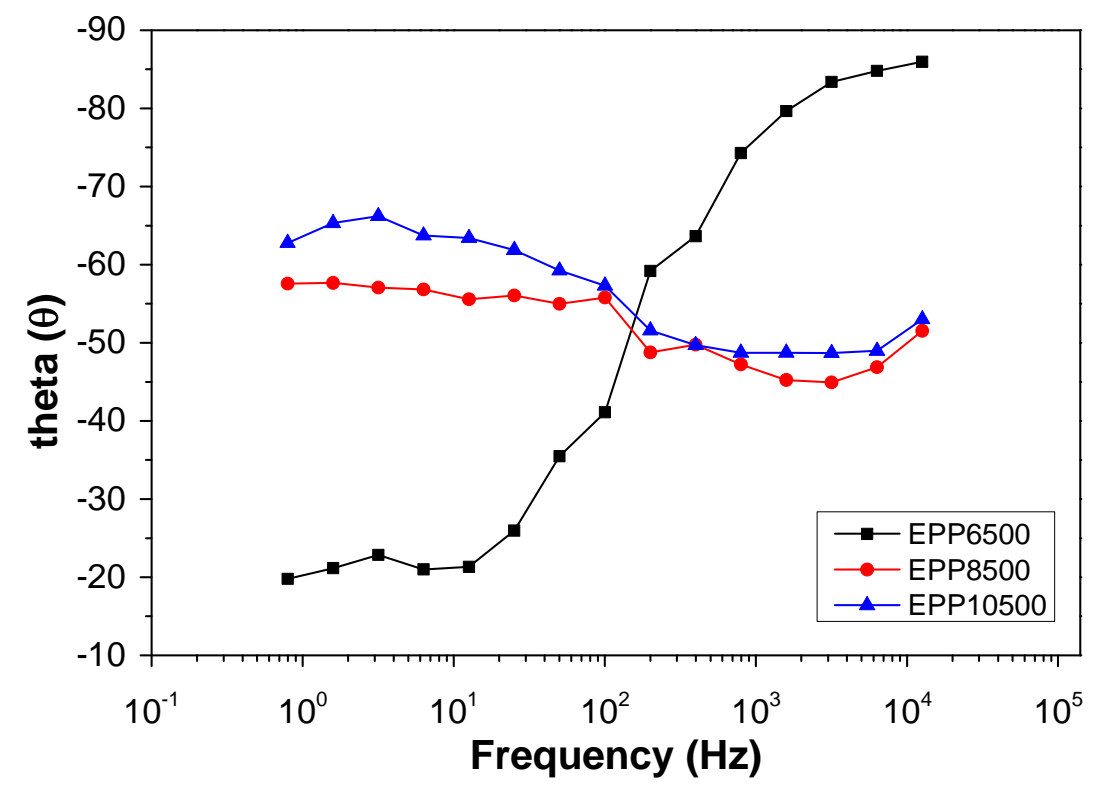

(b)

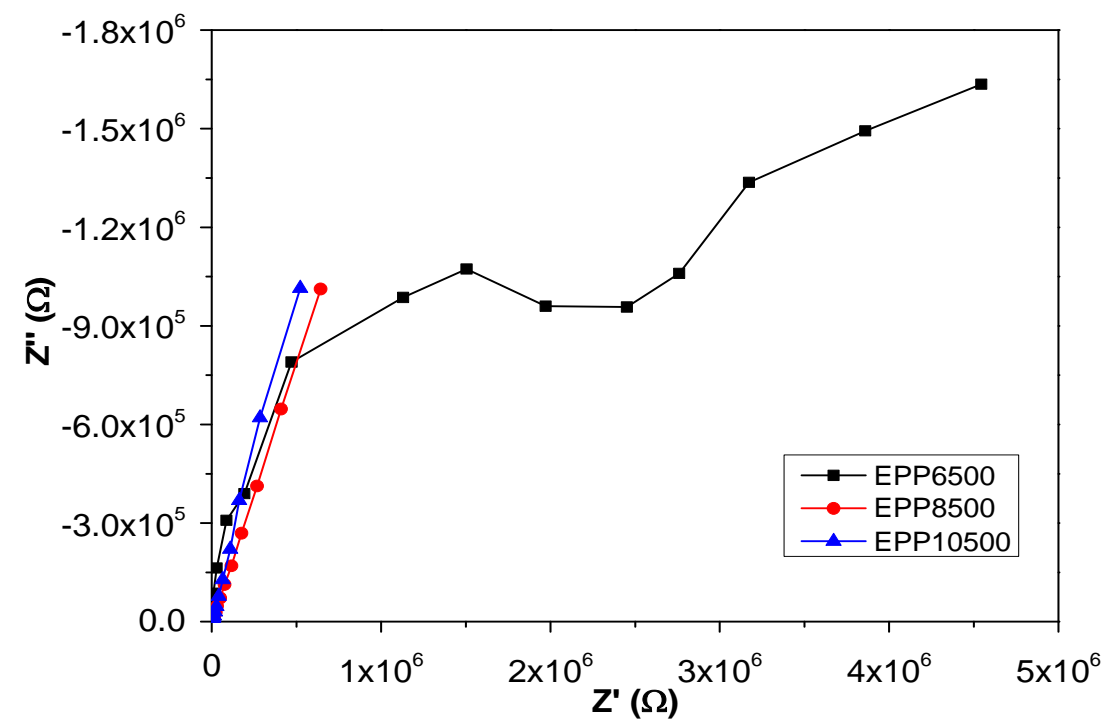

(c)

Figure 10 EIS results of EPP trials (a) Bode plot (b) Bode phase angle plot (c) Nyquist plot

Compared to PU topcoat, the primer with same weight percent of PP10 has higher maximum impedance and, thus, the anti-corrosion property of primer is better than topcoat (Figure 10). All the coatings in EPP series can act as good protective coating for steel. The maximum impedance of the composite coating decreases with increasing PP10 weight percent. Hence, excessive filler is detrimental to the anti- 
corrosion property. From Figure 10 (b), all the coatings are in the phase 1 of degradation and EPP6500 has the best anti-corrosion property and lifetime. One time constant is identified in each curve of different samples in the Nyquist plot. The curve of EPP 6500 is unusual and the reason is still unknown.

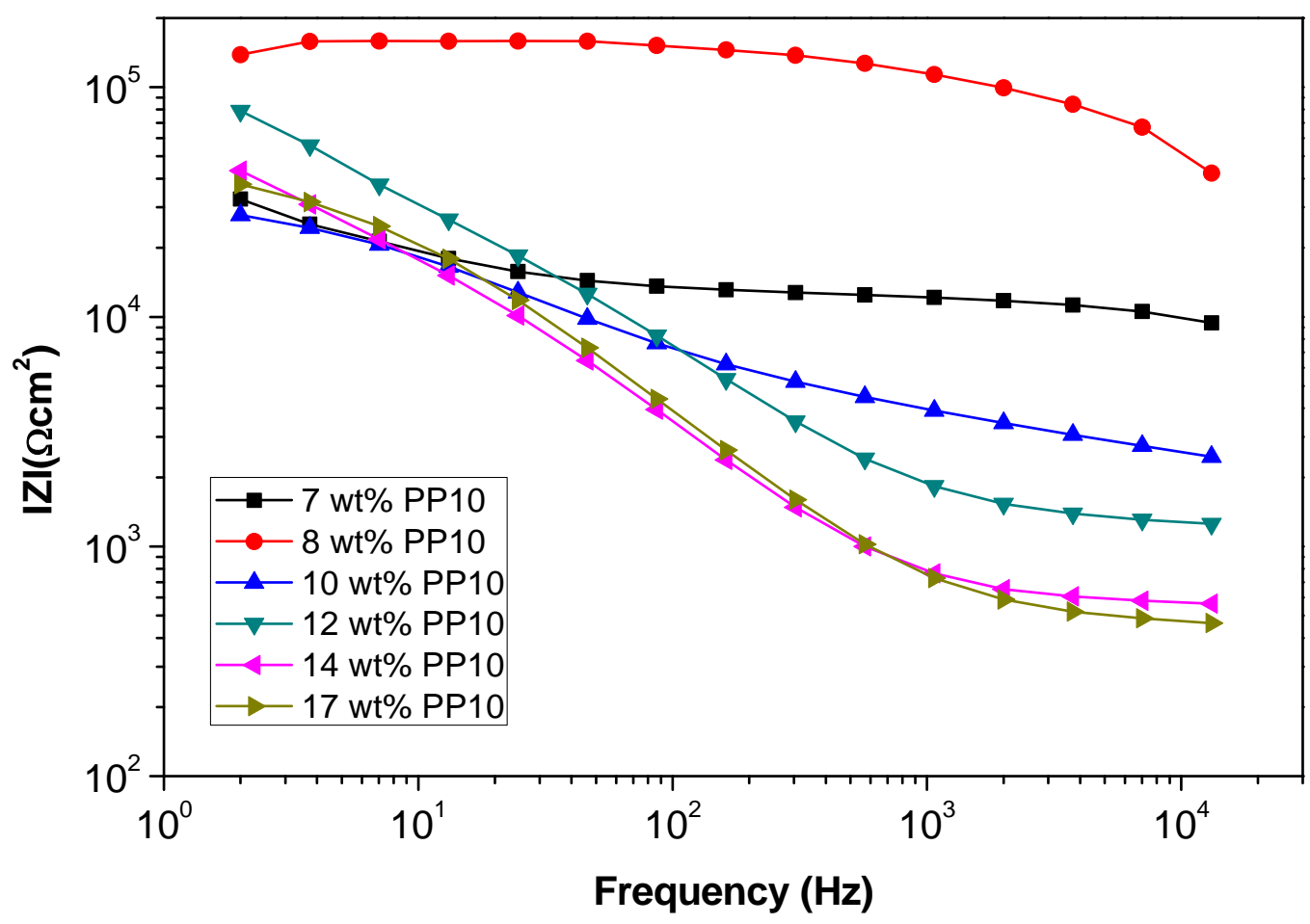

(a)

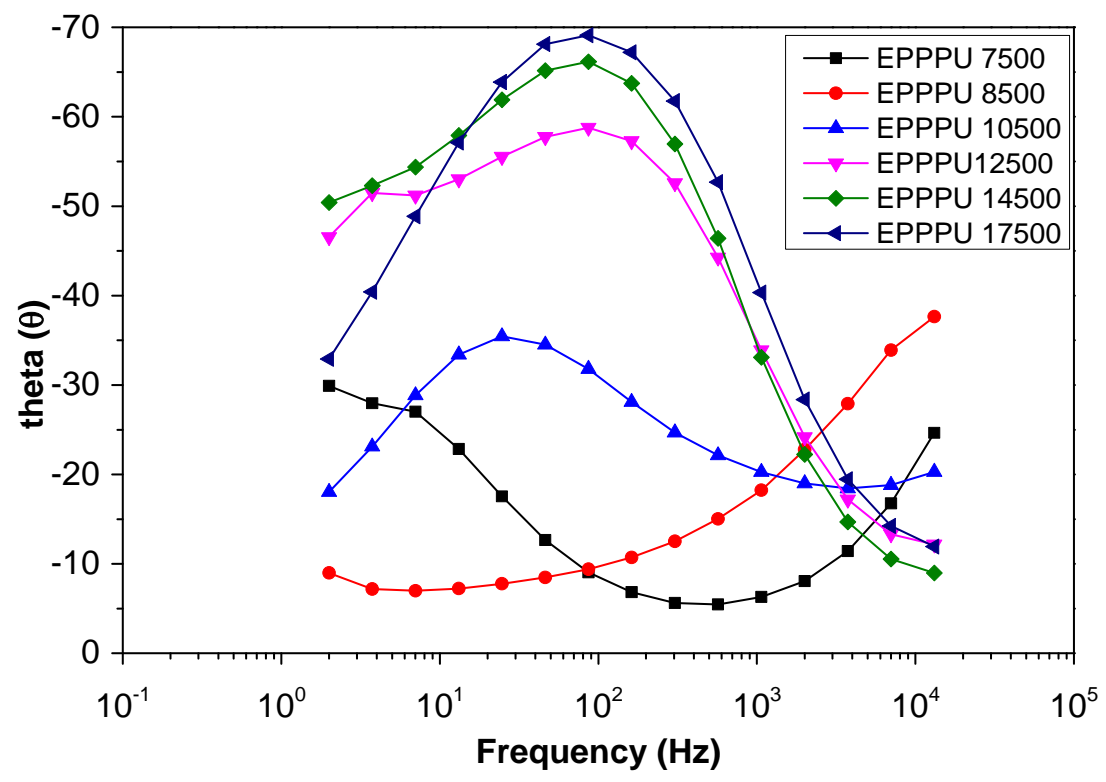

(b) 


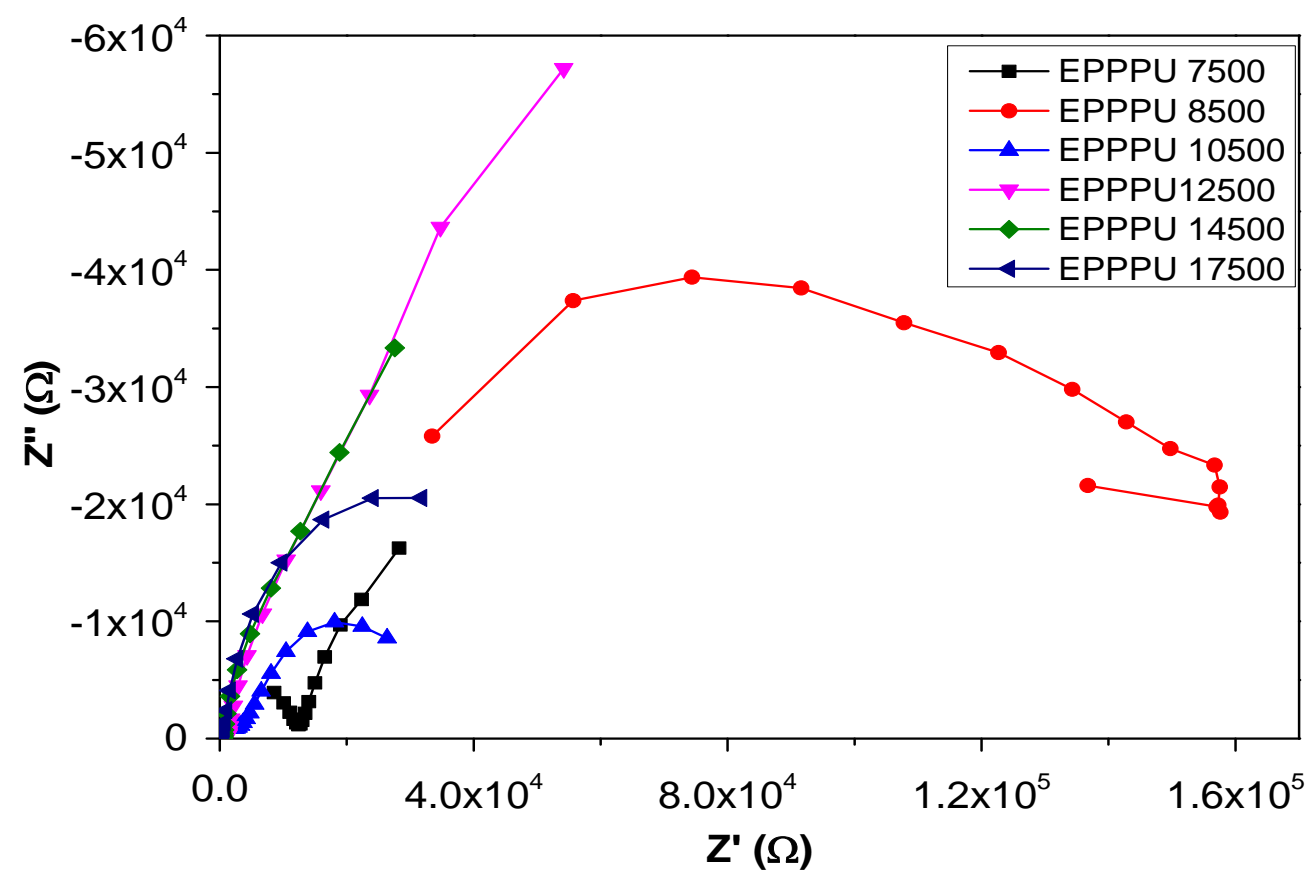

(c)

Figure 11 EIS results of EPPU trials (a) Bode plot (b) Bode phase angle plot (c) Nyquist plot

EPPPU series is a two-layers coating series where primer was applied on the substrate before topcoat. The results show that the maximum impedance of EPPPU is similar to PPPU (Figure 11). In theory, two-layer coating should have better anti-corrosion property than one-layer coating. Therefore, the quality of the two-layer coating is not good enough due to facility limitation. The produced coatings may be heterogeneous and contain defects. From the Nyquist, only EPP7500 has two semi-circles which indicate the loss of barrier property. The quality of EPP7500 is the worst. From the phase angle plot, EPP the quality of EPP12500, 14500 and 17500 seem to be worse than the other as they seem to be in the phase 2 of degradation. Their curves are quite similar to the curves of coatings exposed to corrosive environment for a period of time [20]. The results of the two-layer system are not reliable as the facility to prepare the coating is not ideal. 


\subsubsection{Hybrid filler system}

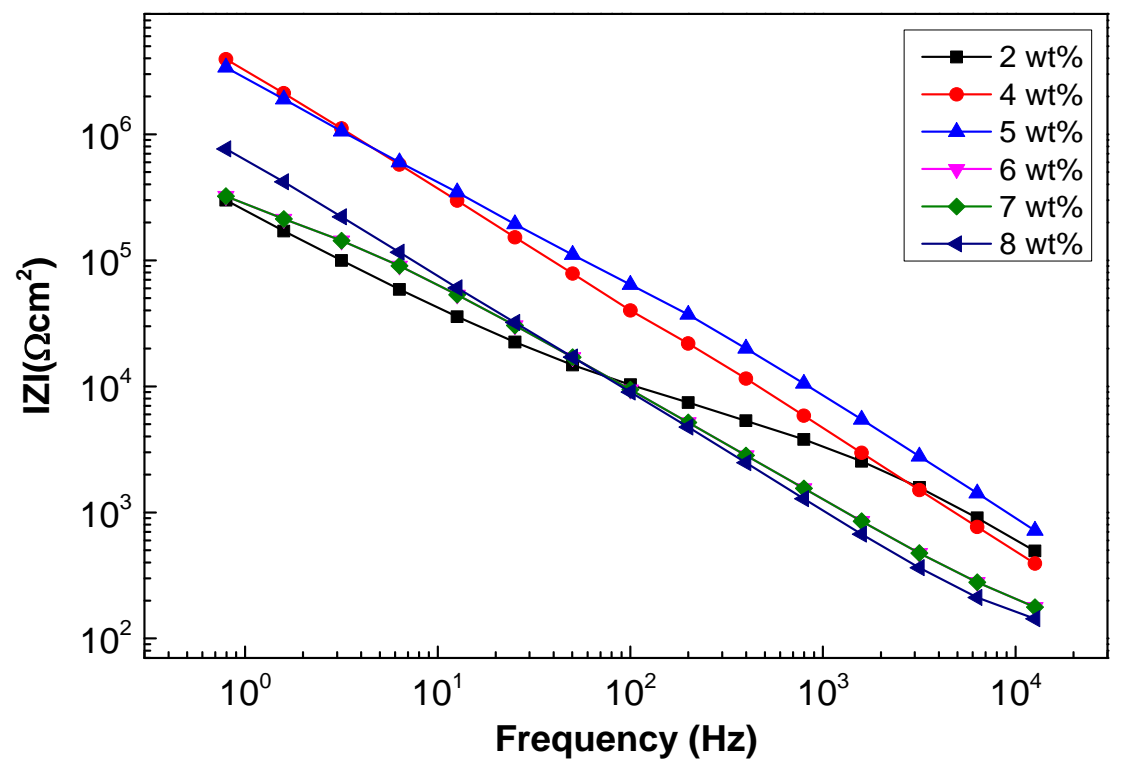

(a)

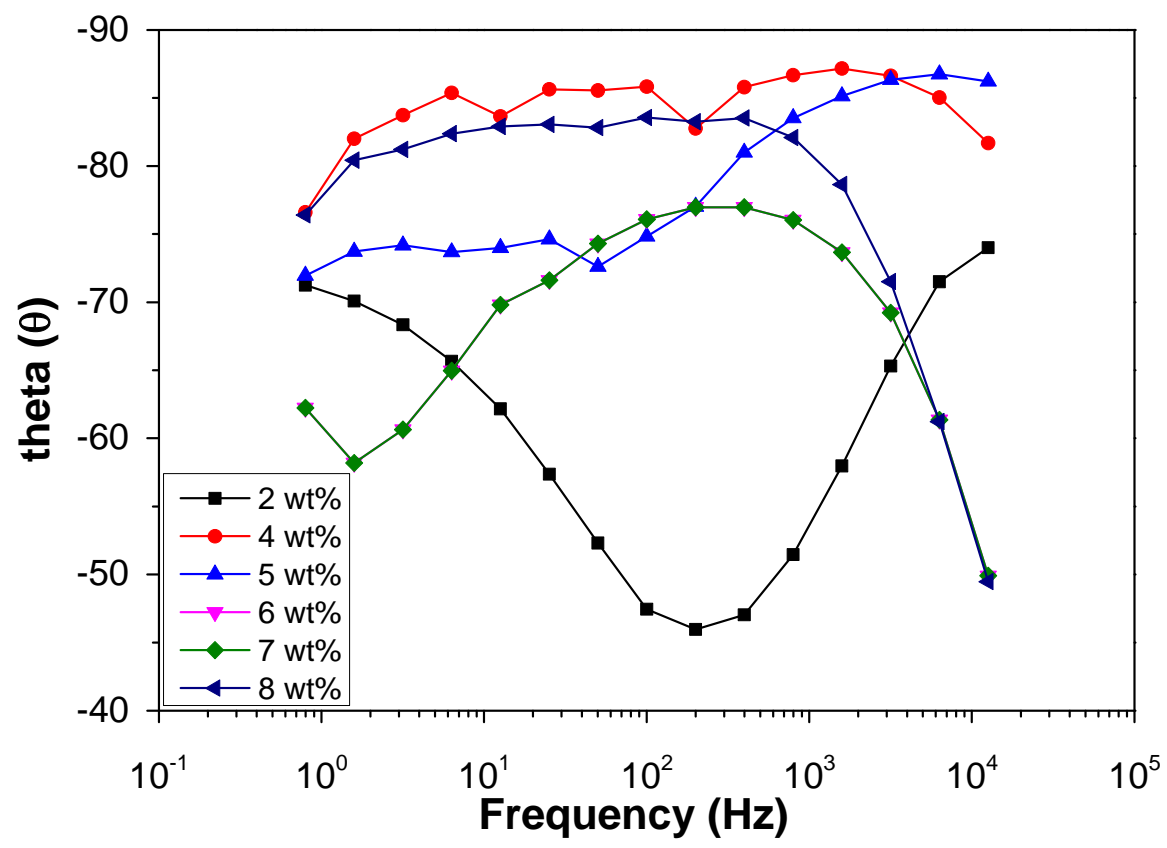

(b) 


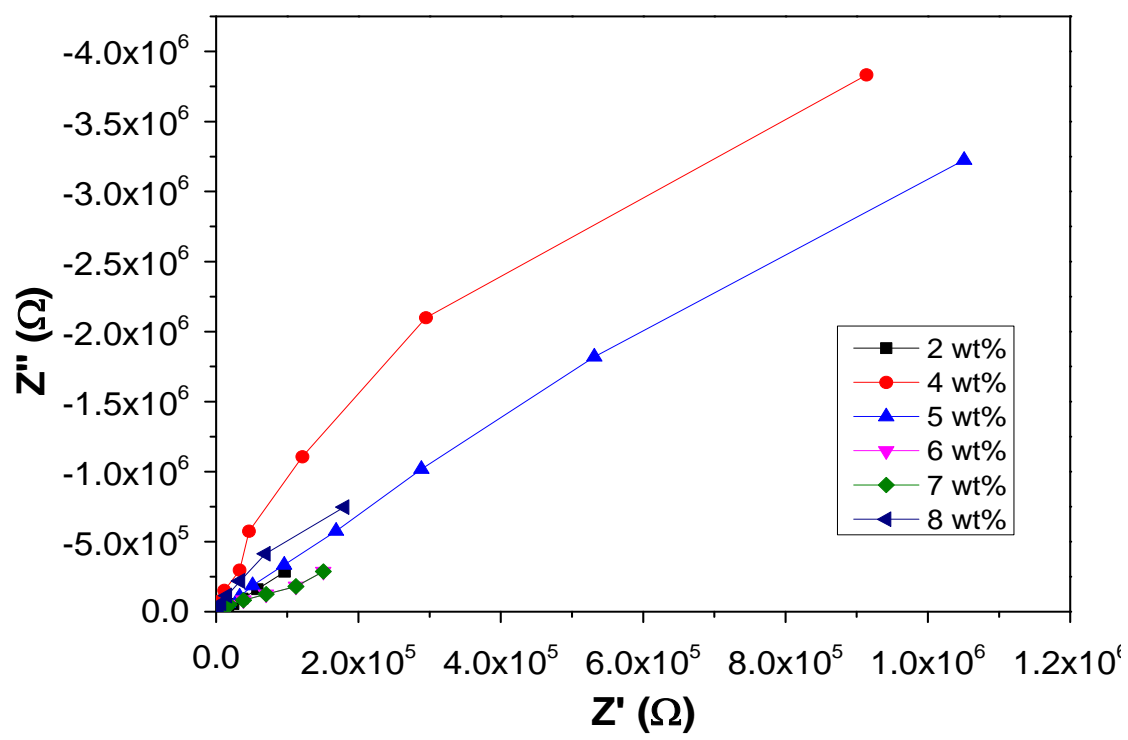

(c)

Figure 12 EIS results of HIVE hybrid filler trials (a) Bode plot (b) Bode phase angle plot (c) Nyquist plot

The EIS results of the hybrid filler primer trial are shown in Figure 12. The anticorrosion property is better than PPPU series and worse than EPP series. The incorporation of hybrid filler actually weakens the anti-corrosion properties due to the high electrical conductivity. The maximum impedance increase with filler loading and then decrease after the loading is greater than $5 \mathrm{wt} \%$. In this frequency range, only the coatings with $4 \mathrm{wt} \%$ and $5 \mathrm{wt} \%$ filler meet the standard of good protective coating. From Figure 12 (b), all the coatings exhibit good protective effect except the $2 \mathrm{wt} \%$ and $7 \mathrm{wt} \%$. The area selected for characterisation may be very heterogeneous where corrosive substance can penetrate through the coating easier. The results from Nyquist plot suggest that all the coatings have good barrier effect.

Table 11 Fit result of hybrid filler series from Randel cell

\begin{tabular}{|c|c|c|c|c|c|c|}
\hline $\begin{array}{c}\text { Filler weight } \\
\text { percent (\%) }\end{array}$ & $\mathbf{R s}(\Omega)$ & $\begin{array}{c}\text { Rs } \\
\text { Error(\%) }\end{array}$ & $\mathbf{C c}(\mathbf{F})$ & $\begin{array}{c}\text { Cc Error } \\
(\%)\end{array}$ & $\mathbf{R c}(\Omega)$ & $\begin{array}{c}\text { Rc Error } \\
\text { (\%) }\end{array}$ \\
\hline 2 & 2875 & 26.314 & $3.89 \mathrm{E}-07$ & 21.331 & $2.70 \mathrm{E}+05$ & 38.81 \\
\hline 4 & 64.29 & 48.354 & $3.84 \mathrm{E}-08$ & 2.7903 & $1.47 \mathrm{E}+07$ & 27.323 \\
\hline 5 & 72.31 & 57.096 & $4.67 \mathrm{E}-08$ & 4.4497 & $1.07 \mathrm{E}+07$ & 38.949 \\
\hline
\end{tabular}




\begin{tabular}{|c|c|c|c|c|c|c|}
\hline 6 & 75.82 & 168.93 & $2.53 \mathrm{E}-08$ & 7.6864 & $5.16 \mathrm{E}+06$ & 25.54 \\
\hline 7 & 143.2 & 25.074 & $1.74 \mathrm{E}-07$ & 8.8187 & $3.42 \mathrm{E}+05$ & 19.476 \\
\hline 8 & 105.4 & 13.839 & $1.81 \mathrm{E}-07$ & 4.1225 & $2.47 \mathrm{E}+06$ & 30.837 \\
\hline
\end{tabular}

The fit results from equivalent circuit are shown in Table 11. The results are used to compare the results of electrical conductivity to distinguish the concept of coating resistance in electrical conductivity and EIS. Randel cell has lower error percentage so the results from that are adopted. However, the two circuits used are not perfect for the system. Development of a more suitable circuit is necessary. In the table, Rs stands for the resistance of the substrate, $\mathrm{Cc}$ is the capacitance of the coating and $\mathrm{Rc}$ represent the resistance of the coating. Comparing the values of resistance in the electrical conductivity and EIS, the values are very different. Therefore, the coating resistance in EIS is an indication of coating resistance against ions but not the current resistance in the electrical conductivity. The coating resistance from EIS cannot be used to represent the electrical conductivity of a coating.

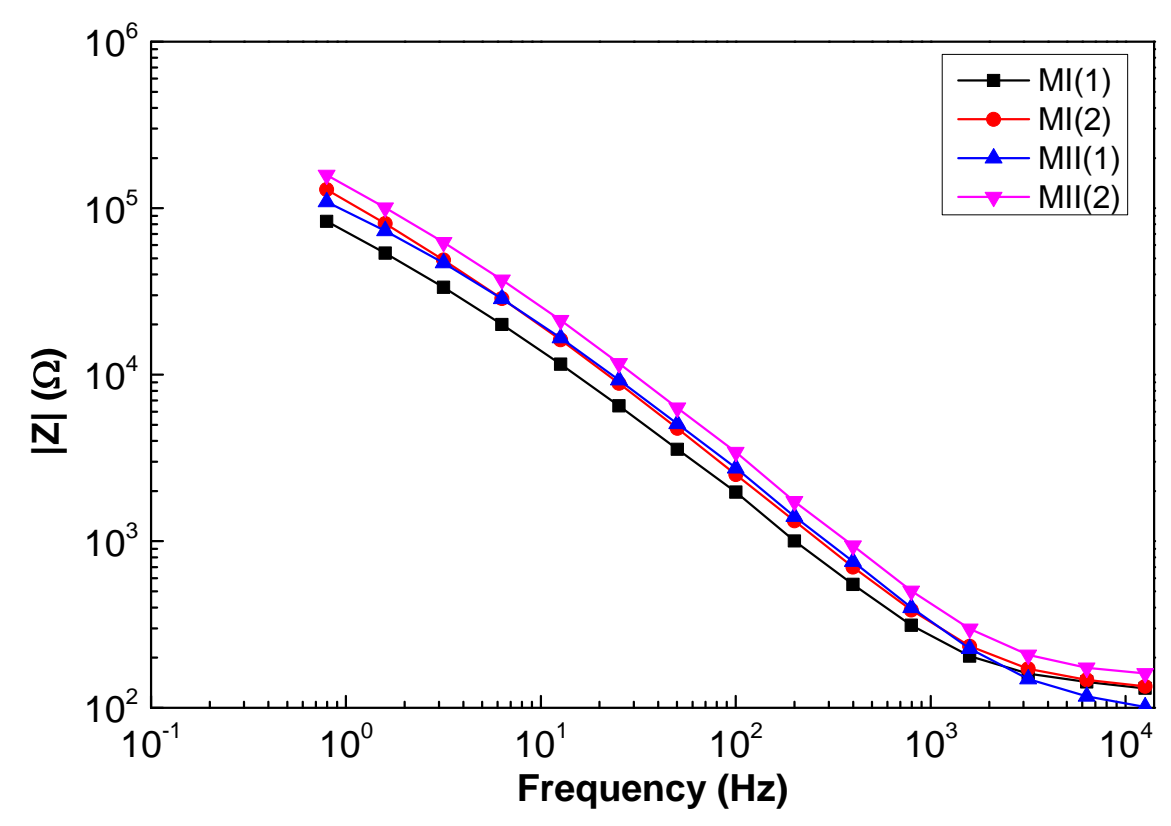

(a) 


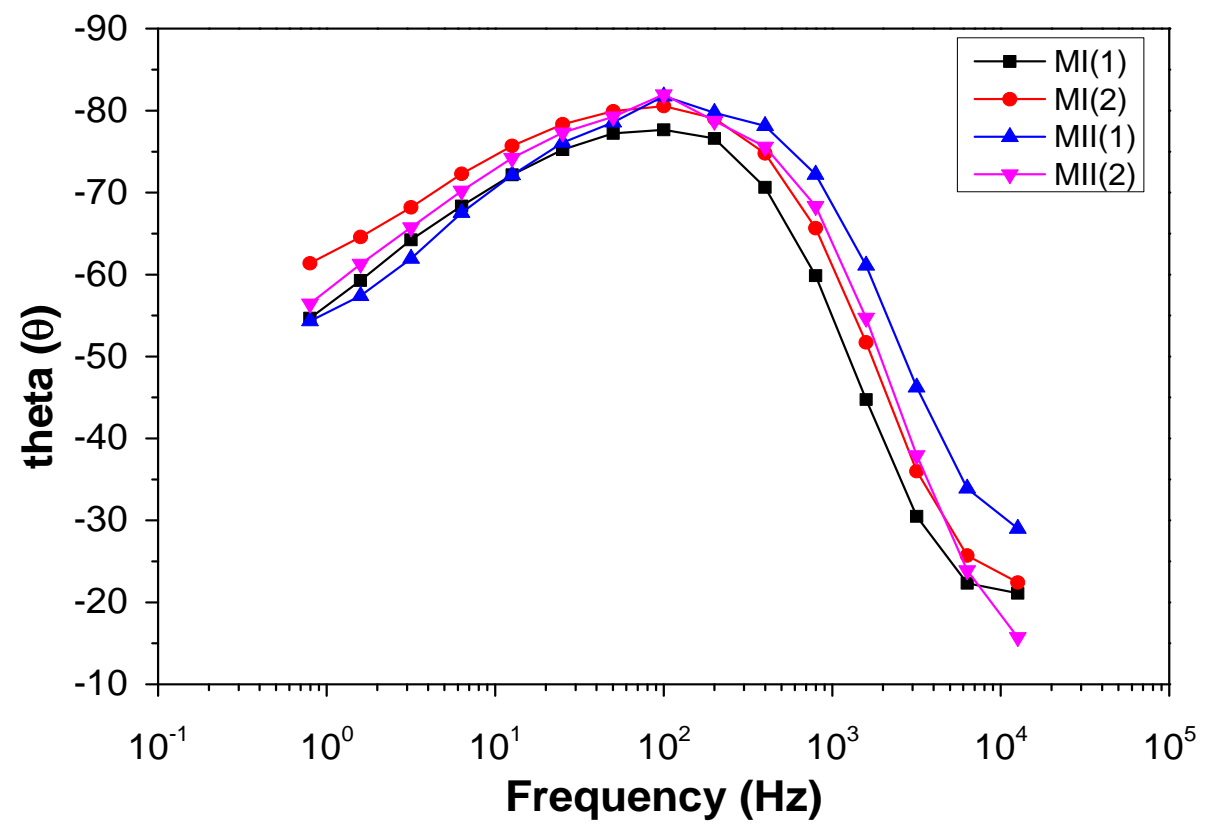

(b)



Figure 13 EIS results of HIVE hybrid filler trials (a) Bode plot (b) Bode phase angle plot (c) Nyquist plot

(c) 
The EIS results of multi-layer coating are shown in Figure 13. The maximum impedance value obtained is similar to the two-layer coating system. However, the phase of degradation is different. Due to the existence of porous EPD coating, the anti-corrosion property is weakened compared to the system without EPD coating. All the coatings are in the phase 2 of degradation and the lifetime is shorter than usual coating. In addition, the defects and heterogeneity induced during preparation account for the weakened anti-corrosion properties as well.

Table 12 The impedance values of different coating systems with similar EIS test conditions

\begin{tabular}{|l|c|c|c|}
\hline \multicolumn{1}{|c|}{ Materials } & Thickness & $\begin{array}{c}\text { Maximum Impedance } \\
\left(\Omega \mathrm{cm}^{2}\right)\end{array}$ & Ref \\
\hline Zinc-rich coating & $5 \mu \mathrm{m}$ & $10^{5}$ & {$[21]$} \\
\hline Commercial PU coating & $65 \mu \mathrm{m}$ & $10^{10}$ & {$[22]$} \\
\hline Different silane coatings & $/$ & $10^{8}-5 \times 10^{8}$ & {$[23]$} \\
\hline Graphene & $\begin{array}{c}2 \text { layers graphene } \\
\text { sheet }\end{array}$ & $6.2 \times 10^{5}$ & {$[24]$} \\
\hline $\begin{array}{l}\text { Functionalized graphene } \\
\text { nanosheets/PU } \\
\text { nanocomposites }\end{array}$ & $25 \mu \mathrm{m}$ & $10^{5.5}$ & {$[25]$} \\
\hline $\begin{array}{l}\text { Graphene oxide } \\
\text { nanosheets/PU } \\
\text { nanocomposites }\end{array}$ & $25 \mu \mathrm{m}$ & $10^{4.75}$ & \\
\hline
\end{tabular}

Table 12 shows the impedance values obtained from different coating systems from the literature. Compared to the graphene based materials reinforced, the coating had better performance with thinner thickness. In addition, the coatings produced also had better performance than the CVD produced graphene sheets. However, the fabricated coatings were much worse than pure commercial PU coating and silane coatings. Thin coating generally has worse corrosion resistance than thick coating but the relationship between thickness and the impedance is not clear. The performance of the fabricated coatings can be improved by optimising the coating techniques. 


\subsection{The surface characterisation of the coated surfaces}

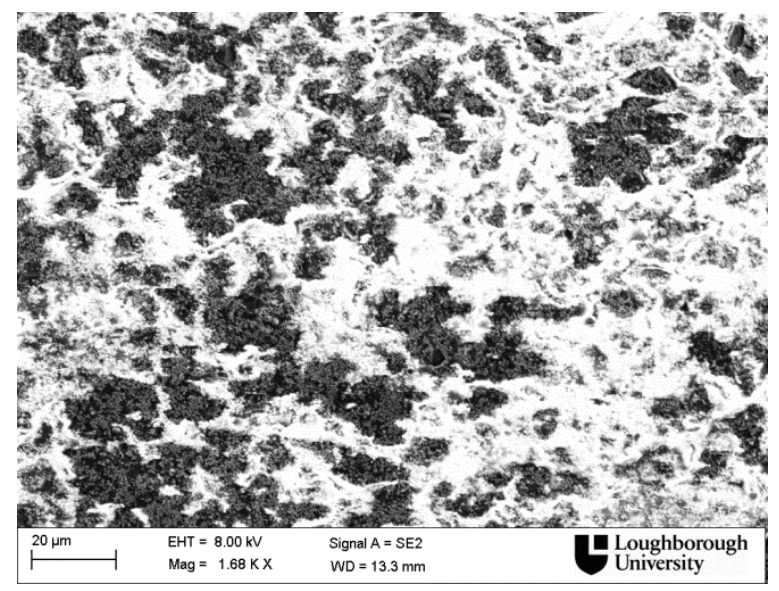

(a)

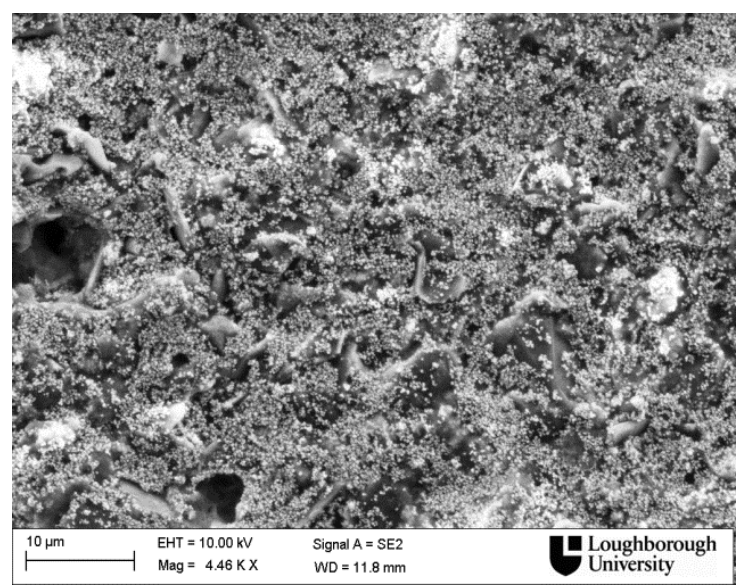

(b)

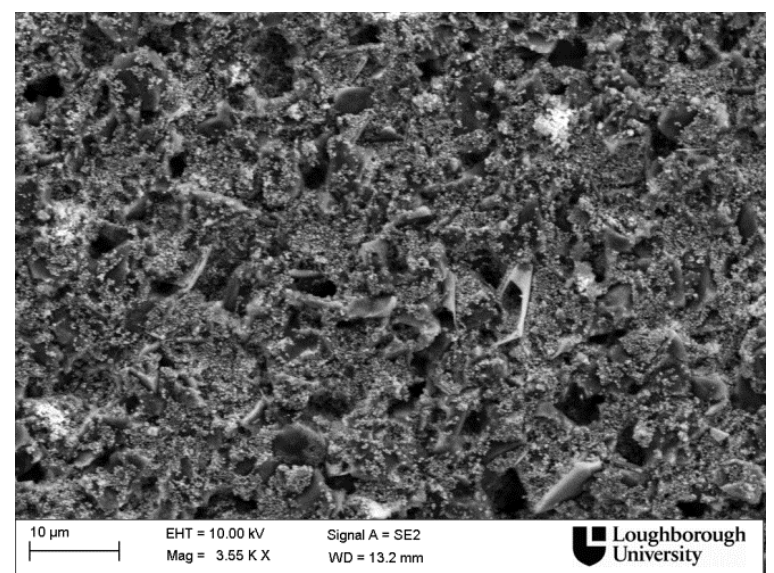

(c)

Figure 14 Example FEGSEM images of (a) PPPU 6500 (b) PPPU 10500 (c) PPU14500 FEGSEM is used to characterize the surface of the coating (Figure 14). From the images, coatings with higher weight percent of filler have less polymer coverage on the surface. Therefore, the porous nature of the coating surface leads to poor anticorrosion capacity. Although polymer may present between the gaps of the fillers, the corrosive medium can still penetrate through the coating easier than the coating with proper polymer coverage. The presence of high percentage of filler may affect the cure of the coating to hinder the polymer chains to react with each other for the formation of polymer network. Hence, the cure kinetic of reinforced PU coating needs to be investigated to reveal the effect of filler on the cure of coating. 


\section{Conclusions}

Hybrid filler system has the best electrical conductivity and acceptable anti-corrosion capacity. The best filler ratios is TEG:MWCNT=1:1. Multi-layer coating system consist of EPD coating, conductive primer and conductive topcoat has superior electrical conductivity than single layer primer or topcoat. However, the anticorrosion capacity is worse than single layer system due to the limited facility of coating preparation. The key to improve electrical conductivity is to reduce the distance between the conductive particles. The strategy of using particles with larger diameter and high aspect ratios to form conductive network is recommend. The cure of the coating may be affected significantly by the fillers. The study of cure kinetic of the composite is necessary.

\section{Acknowledgement}

We thank TATA Steel and the PhD scholarship of Loughborough University for providing the funding for this work

\section{References}

[1] H. Chen, T.N. Cong, W. Yang, C. Tan, Y. Li, Y. Ding, Progress in electrical energy storage system: A critical review, Prog. Nat. Sci. 19 (2009) 291-312.

[2] F. Mclarnon, E. Cairns, Energy storage, Ann Rev Energy. 14 (1989).

[3] Electrical Energy Storage project team, Electrical Energy Storage White paper, 2009.

[4] EA Technology, Review of Electrical Energy Storage Technologies and Systems and of their Potential for the UK, (2004).

[5] E. Mattsson, Basic corrosion technology for scientists and engineers, Ellis Horwood. Halsted Press, 1989.

[6] G.H. Koch, M.P. Brongers, N.G. Thompson, Y.P. Virmani, J.H. Payer, Corrosion cost and preventive strategies in the United States, 2002.

[7] G. Wranglen, An Introduction to Corrosion and Protection of Metals, Chapman and Hall, London, 1985. 
[8] A. Amirudin, D. Thierry, Application of electrochemical impedance spectroscopy to study the degradation of polymer-coated metals, Prog. Org. Coatings. 26 (1995) 1-28.

[9] W. Funke, Polymeric Materials for Corrosion Confrol, in: R.A. Dickie, F.L. Floyd (Eds.), Am. Chem. Soc. Symp., USA, 1986: p. 222.

[10] A S. Woodman, E.B. Anderson, K.D. Jayne, M.C. Kimble, Development of corrosion-resistant coatings for fuel cell bipolar plates, Proc. AESF Annu. Tech. Conf. (1999) 717-725.

[11] S. Bose, T. Kuila, M.E. Uddin, N.H. Kim, A.K.T. Lau, J.H. Lee, In-situ synthesis and characterization of electrically conductive polypyrrole/graphene nanocomposites, Polymer. 51 (2010) 5921-5928.

[12] J. Canales, M.E. Muñoz, M. Fernández, A. Santamaría, Rheology, electrical conductivity and crystallinity of a polyurethane/graphene composite: Implications for its use as a hot-melt adhesive, Compos. Part A Appl. Sci. Manuf. 84 (2016) 9-16.

[13] C.H. Chang, T.C. Huang, C.W. Peng, T.C. Yeh, H.I. Lu, W.I. Hung, et al., Novel anticorrosion coatings prepared from polyaniline/graphene composites, Carbon 50 (2012) 5044-5051.

[14] D. Prasai, J.C. Tuberquia, R.R. Harl, G.K. Jennings, B.R. Rogers, K.I. Bolotin, Graphene: corrosion-inhibiting coating., ACS Nano. 6 (2012) 1102-1108.

[15] Y. Tong, S. Bohm, M. Song, Carbon Based Coating on Steel with Improved Electrical Conductivity, Austin J. Nanomedicine Nanotechnol. 3 (2015) 1-7.

[16] J. Jin, Y. Lin, M. Song, C. Gui, S. Leesirisan, Enhancing the electrical conductivity of polymer composites, Eur. Polym. J. 49 (2013) 1066-1072.

[17] J.M. Costa, A.D. Mercer, Progress in the Understanding and Prevenfion of Corrosion, The Institute of Materials, London, UK, 1993.

[18] J.R. Scully, S.T. Hensley, CORROSION/93, in: National Association of Corrosion Engineers, New Orleans, LA, USA, n.d.: p. Paper No. 359. 
[19] V. Lavaert, M. Moors, E. Wettinck, An EIS study of the influence of imperfections on the corrosion behaviour of an organic coated steel system, J. Appl. Electrochem. 32 (2002) 853-857.

[20] L. Jianguo, G. Gaoping, Y. Chuanwei, EIS study of corrosion behaviour of organic coating/Dacromet composite systems, Electrochim. Acta. 50 (2005) $3320-3332$.

[21] J.H. Park, T.H. Yun, K.Y. Kim, Y.K. Song, J.M. Park, The improvement of anticorrosion properties of zinc-rich organic coating by incorporating surfacemodified zinc particle, Prog. Org. Coatings. 74 (2012) 25-35.

[22] Y. González-García, S. González, R.M. Souto, Electrochemical and structural properties of a polyurethane coating on steel substrates for corrosion protection, Corros. Sci. 49 (2007) 3514-3526.

[23] M.F. Montemor, a. M. Simões, M.G.S. Ferreira, B. Williams, H. Edwards, The corrosion performance of organosilane based pre-treatments for coatings on galvanised steel, Prog. Org. Coatings. 38 (2000) 17-26.

[24] R.K. Singh Raman, P. Chakraborty Banerjee, D.E. Lobo, H. Gullapalli, M. Sumandasa, A. Kumar, et al., Protecting copper from electrochemical degradation by graphene coating, Carbon N. Y. 50 (2012) 4040-4045.

[25] M. Mo, W. Zhao, Z. Chen, Q. Yu, Z. Zeng, X. Wu, et al., Excellent tribological and anti-corrosion performance of polyurethane composite coatings reinforced with functionalized graphene and graphene oxide nanosheets, RSC Adv. 5 (2015) 56486-56497. 